\title{
Entre el realismo y el constructivismo: una forma de comprender la justicia transicional en Colombia**
}

\section{Between Realism and Constructivism: A Way to Understanding Transitional Justice in Colombia}

RESUMEN

Una de las cuestiones más importantes para la comprensión de la justicia de transición se deriva de la relación de tensión existente entre Derecho y poder de cara a las necesidades de justicia como reclamo a graves violaciones a los derechos humanos cometidas en periodos de conflictos armados, guerras civiles o dictaduras. Dicha relación de tensión se explicó inicialmente haciendo gala de la dicotomía entre realismo e idealismo.

Más allá de tomar partido entre una y otra teoría, a través de este documento se pretende argumentar que la configuración del modelo de justicia transicional en Colombia se ha dado a partir de la interacción entre diversos enfoques y miradas, haciendo un énfasis particular en las teorías realista y constructivista. Así, se propone que la comprensión y la legitimación de los mecanismos de transición adoptados en el país pueden explicarse desde el realismo jurídico, el realismo político y la mirada constructivista. Tal propuesta puede ayudarnos a comprender e interpretar los avances o retrocesos en la implementación de las medidas creadas para la superación del conflicto armado y la reconciliación nacional.

PALABRAS CLAVE

Justicia transicional, enfoques, realismo jurídico, realismo político, constructivismo.

* Abogada de la Universidad de San Buenaventura de Cali. Magíster en Derechos Humanos y Democratización de la Universidad Externado de Colombia. Docente investigadora del programa de Derecho de la Fundación Universitaria Católica Lumen Gentium-Unicatólica, Grupo de Investigación en Derecho y Ciencias Políticas, Colombia. Correo de contacto: vbetancourt@ unicatolica.edu.co. ORCID: https://orcid .org/0000-0002-6004-3980.

** Recibido el 13 de mayo del 2020, aprobado el 31 de agosto del 2020.

Para citar el artículo: Entre el realismo y el constructivismo: una forma de comprender la justicia transicional en Colombia. En Revista Derecho del Estado, Universidad Externado de Colombia. N. ${ }^{\circ} 48$, enero-abril de 2021, 113-148.

DOI: https://doi.org/10.18601/01229893.n48.05 
ABSTRACT

One of the most important matters for understanding transitional justice stems from the tension between Law and Power in the face of the need for justice as a response to grave violations of human rights committed in times of armed conflict, civil war and dictatorship. Said tension was initially explained by displaying the dichotomy between realism and idealism.

Beyond favouring one theory or another, this document will highlight how Colombia's transitional justice model has formed through the interaction between different approaches and perspectives, making particular emphasis on the realist and constructivist theories. Therefore, it is proposed that the comprehension and legitimization of the transitional mechanisms that were adopted in the country can be explained through legal realism, political realism, and the constructivist perspective. This proposal can help us understand and interpret the advances or setbacks in the implementation of the measures that were set in place in order to overcome the armed conflict and promote national reconciliation.

KEYWORDS

Transitional justice, approaches, legal realism, political realism, constructivism.

SUMARIO

Introducción. I. Primer enfoque: realismo jurídico, el Derecho como ingeniería social. A. Realismo jurídico transicional en Colombia. 1. El papel de la Corte Constitucional en la adopción de mecanismos de transición. 2. La Jurisdicción Especial para la Paz (JEP). 3. Constitucionalización de la Justicia Transicional en Colombia. II. Segundo enfoque: realismo político. A. Realismo político transicional en Colombia. 1. La política de la Seguridad Democrática. 2. El reconocimiento político de las víctimas del conflicto armado interno. 3. La negociación con la guerrilla de las FARC-EP. 4. La llegada al poder de Iván Duque Márquez. III. Tercer enfoque: la apuesta constructivista. A. La participación de las víctimas y la sociedad civil en la configuración del modelo de justicia transicional. B. El asesinato sistemático de los líderes defensores de derechos humanos. Conclusión. Bibliografía

\section{INTRODUCCIÓN}

Uno de los campos más importantes y tal vez menos desarrollados de la justicia transicional es el entendimiento de los enfoques y miradas teóricas que inciden en la comprensión, legitimación y efectividad de los modelos de transición. En ese sentido, algunos autores, dentro de los que se destacan particularmente 
Ruti Teitel ${ }^{1}$ y Gabriel Ignacio Gómez ${ }^{2}$-sin descontar otros aportes teóricos y doctrinales de las organizaciones nacionales e internacionales ${ }^{3}-$, han permitido la identificación y el análisis de algunos enfoques a saber: el enfoque realista, el idealista y el constructivista.

El primero de ellos está enmarcado en la idea de que los cambios políticos constituyen el primer paso para producir la transición ${ }^{4}$ o en nuestro caso la superación del conflicto armado interno. Dicha teoría, construida esencialmente desde la mirada política, afirma que el modelo de transición es resultado de lo que se puede hacer según los intereses y voluntad política en juego. Por su parte, el enfoque idealista afirma que es el Derecho quien a través de la creación de instrumentos jurídicos orienta la transición. Dicho modelo rescata la necesidad de respetar los más altos estándares en materia de lucha contra la impunidad y garantía de los derechos humanos desarrollados internacionalmente ${ }^{5}$.

Al margen de esta disputa, el enfoque constructivista propone que la búsqueda de la justicia en periodos de transición se explica mejor en términos de equilibrio de poder ${ }^{6}$, esto es, aceptando que la justicia transicional es un campo de tensión en el cual diferentes actores combaten por imponer sus

1 Destacando dos trabajos de la autora, a saber: Teitel, R. Justicia transicional. Traducido por M. J. Viana. $1^{\text {a }}$ edición en castellano. Bogotá: Universidad Externado de Colombia, 2017. ISBN 978-958-772-760-9; y Teitel, R. Genealogía de la justicia transicional. Human Rights Journal. 2003, vol. 16, pp. 69-94.

2 Destacando dos de sus trabajos más importantes con relación al enfoque de justicia transicional desde abajo y la visión constructivista del campo: GómEz, G. Justicia transicional en disputa: Una perspectiva constructivista sobre las luchas por la verdad, la justicia y la reparación en Colombia, 2002-2012. $1^{\text {a }}$ ed. Medellín: Universidad de Antioquia, 2014. ISBN 978-958-714615-8 y, Gómez, G. Justicia transicional "desde abajo": un marco teórico constructivista crítico para el análisis de la experiencia colombiana. Revista Co-herencia. 2013, (19), 137-166 [fecha de consulta: 28 de febrero de 2019]. IsSN 1794-5887.

3 Aquí cabe mencionar, como se verá más adelante en el texto, los aportes a la discusión gestados por organismos de la onU (la Oficina del Alto Comisionado para la Paz, el Consejo de Derechos Humanos y el Comité de Derechos Humanos) y algunas organizaciones no gubernamentales del orden nacional, como el Centro de Estudios en Derecho, Justicia y Sociedad (Dejusticia), el Centro de Investigación y Educación Popular (CINEP) y la Fundación Paz y Reconciliación.

4 Teitel, R. Justicia transicional. Traducido por M. J. Viana. $1^{\text {a }}$ edición en castellano. Bogotá: Universidad Externado de Colombia, 2017. ISBN 978-958-772-760-9.

5 En ese sentido, se debe tener en cuenta el Conjunto de principios actualizado para la protección y la promoción de los derechos humanos mediante la lucha contra la impunidad adoptado por la Organización de las Naciones Unidas en 2005. TeITEL, R. Genealogía de la justicia transicional. Human Rights Journal. 2003, vol. 16, pp. 69-94. Así, se coincide con la tercera fase de la justicia transicional propuesta por la autora, denominada el "estado estable de la justicia transicional", el cual coincide con la normalización de la justicia transicional en virtud de la creación de estándares internacionales de protección del individuo en contextos de guerra y vulneración de derechos humanos. Dicha normalización está representada jurídicamente en el desarrollo del derecho internacional humanitario y el derecho internacional de los derechos humanos.

6 Teitel, R. Justicia transicional. Traducido por M. J. Viana. $1^{\text {a }}$ ed. en castellano. Bogotá: Universidad Externado de Colombia, 2017. ISBN 978-958-772-760-9. 
versiones sobre la paz o la justicia ${ }^{7}$. Orientada desde la perspectiva de las ciencias sociales, esta teoría realza el papel de los actores no estatales como las organizaciones y las redes de derechos humanos, en su lucha por contar con un modelo basado en el reconocimiento de las víctimas del conflicto y en la reconciliación nacional.

Así, el análisis de los enfoques teóricos guía especialmente la comprensión de la justicia de transición y permite explicar la configuración de modelos nacionales de acuerdo a su propio contexto. Para el caso colombiano se tratará de propiciar el estudio a partir de tres enfoques a saber: (1) el realismo jurídico, (2) el realismo político y (3) el enfoque constructivista.

Dicha elección no significa desestimar la importancia de la propuesta idealista, sino más bien considerar que la aplicación efectiva de los estándares internacionales de protección de derechos humanos ha dependido de las condiciones sociopolíticas imperantes en ciertos momentos de la historia nacional, delimitando el diseño de medidas para la superación del conflicto interno y la reparación integral a las víctimas. No en vano, De Greiff ${ }^{8}$ afirma que pese a haberse convertido en una especie de "herramienta universal", la justicia transicional es un campo que nació de la práctica, y por tanto las realidades de contexto en el que éstos instrumentos se aplican, condicionan la implementación y puesta en marcha de las medidas adoptadas, las cuales no sólo incluyen mecanismos para judicializar las violaciones a los derechos humanos, sino también medidas para el esclarecimiento de la verdad, la reparación a las víctimas, y algunos aspectos de reforma institucional ${ }^{9}$. Esta apuesta pondría en cuestión la idea de que la justicia transicional ha ido evolucionando gracias a los límites al poder impuestos por el derecho internacional de los derechos humanos y el derecho penal internacional ${ }^{10}$. Comprender el caso colombiano desde las miradas realista y constructivista nos permitirá reconocer que la interpretación judicial, el voluntarismo estatal, y el reconocimiento del Derecho como construcción social, son fenómenos intrínsecos en las apuestas de transición para Colombia.

De esta manera, más allá de hacer gala de la importancia de sistemas teóricos generales ${ }^{11}$, el objetivo general de esta propuesta es analizar las complejas

7 Gómez, G. Justicia transicional en disputa: Una perspectiva constructivista sobre las luchas por la verdad, la justicia y la reparación en Colombia, 2002-2012. $1^{\text {a }}$ ed. Medellín: Universidad de Antioquia, 2014. ISBN 978-958-714-615-8.

8 De GreIfF, P. Algunas reflexiones acerca del desarrollo de la Justicia Transicional. Anuario de Derechos Humanos, 2011, (7), 17-39 [consultado el 2 de febrero de 2019]. Disponible en: https://corteidh.or.cr/tablas/r29408.pdf.

9 Ibídem, p. 18.

10 IBARRA, A. Justicia Transicional: la relación Derecho-Poder en los momentos de transición. Revista de Derecho, 2016, (45), 237-261 [consultado el 4 de septiembre de 2020]. Disponible en: http://rcientificas.uninorte.edu.co/index.php/derecho/article/view/7176/7978.

11 Bonilla, E. y Rodríguez, P. Más allá del dilema de los métodos: la investigación en ciencias sociales [en línea]. $3^{\mathrm{a}}$ ed. Bogotá: Grupo Editorial Norma, Universidad de los Andes, s.f. 
realidades sociopolíticas y jurídicas que se han hecho evidentes en la configuración del modelo transicional colombiano a la luz de los enfoques propuestos.

El análisis del modelo colombiano a partir de las teorías resaltadas se alcanza a través de tres objetivos específicos: (1) comprendiendo la justicia transicional desde cada postura teórica, (2) legitimando el modelo nacional de acuerdo a las virtudes de cada enfoque y (3) destacando algunos avances o estancamientos en la implementación del mismo.

\section{PRIMER ENFOQUE: REALISMO JURÍDICO, EL DERECHO COMO INGENIERÍA SOCIAL}

Según Recalde ${ }^{12}$, el realismo jurídico surge en el periodo de entre guerras 1918-1930, bajo la idea predominante de que el Derecho está especialmente determinado por los hechos, que al ser conocidos e interpretados en las cortes, permiten vincular la mirada sociológica al razonamiento de los jueces. El Derecho no sería entonces una disciplina autosuficiente y autocontenida, sino que como fenómeno social se vale de otras ciencias -especialmente de las ciencias sociales- para realizar un trabajo interdisciplinario que permita entender la realidad y el espíritu del tiempo.

Otra de las virtudes del realismo jurídico es el replanteamiento de la historia del Derecho en términos de su correspondencia con las realidades palpables. Los realistas estuvieron especialmente interesados en el análisis de las relaciones de función y disfunción entre la ley y lo social ${ }^{13}$, reivindicando la necesidad de valorar la realidad de acuerdo a las necesidades y circunstancias sociales tangibles.

Teóricamente hablando, hay varias corrientes que se destacan en la comprensión del realismo jurídico. En este caso, se rescatan algunas ideas de las propuestas estadounidense, escandinava, italiana y francesa.

Según la primera, y siguiendo a autores como Pound, por ejemplo, se tiene que aun cuando el Derecho tiene una estructura lógica, éste es un instrumento para la vida social y su eficacia debe medirse de acuerdo a la capacidad para realizar fines humanos, dentro de ese constante fluir que es siempre el río de la historia ${ }^{14}$.

Disponible en: https://laboratoriociudadut.files.wordpress.com/2018/05/mas-alla-del-dilema-delos-metodos.pdf..

12 ReCalde, G. Repensando la iushistoria: aportes del realismo jurídico a la discusión en Revista de Derecho, 2016, vol. 1, pp. 1-16 [fecha de consulta: 8 de agosto de 2019]. Disponible en: https://una.uniandes.edu.co/images/pdf-edicion1/articulos/Recalde2016-Artculo-UNA-Revistade-Derecho.pdf.

13 Ídem, p. 8.

14 CAmpos, F. Nociones fundamentales del realismo jurídico. Revista de Ciencias Jurídicas. 2010, 122, 191-220 [fecha de consulta: 20 de junio de 2019]. Disponible en: https://revistas.ucr. ac.cr/index.php/juridicas/article/view/13562/12850. 
Por su parte, Karl Llewellyn también aporta al movimiento realista estadounidense, proponiendo la concepción del Derecho como medio para fines sociales y no como fin en sí mismo. De esta manera, entiende la sociedad como un fluir típicamente más rápido que el Derecho, existiendo siempre la probabilidad de que cualquier porción del Derecho necesite ser reexaminada, para ver hasta qué punto se adecúa a la sociedad a la que pretende servir ${ }^{15}$.

Dichas posturas estadounidenses se basan en el papel fundamental de los jueces, quienes representan lo que el Derecho significa en cada caso o periodo en concreto, es decir, uno de los principales enfoques del realismo jurídico se posa sobre la función o adjudicación judicial y la respuesta a la pregunta: ¿cómo resuelven los jueces casos concretos basados en los precedentes y los hechos particulares de cada uno?

En la propuesta escandinava se debe tener en cuenta en primer lugar la postura de Hagerstrom, según la cual la única realidad cognoscible son los hechos ${ }^{16}$. De tal manera que cualquier respuesta metafísica sobre lo que es el Derecho debe ser desestimada en tanto basada en propuestas sobrenaturales acerca del bien o la justicia.

Esta tesis general será retomada por sus contemporáneos, con algunos aportes particulares. Así, Olivecrona añade al enfoque realista un análisis del derecho a partir del lenguaje ético y jurídico. En ese sentido, el autor destaca las funciones sociales del lenguaje, manifestando el poder que ostentan las expresiones lingüísticas en el establecimiento de derechos, deberes y capacidades jurídicas ${ }^{17}$. De esta manera, resalta el papel de la psicología en la creación del Derecho, el cual debe ser entendido como lo que se acepta como válido u obligatorio por parte de los sujetos que se relacionan jurídicamente y le dan sentido a sus normas. Lundsted, por su parte, integra la idea de bienestar social "social welfare", es decir, en términos actuales un enfoque de "política del Derecho" en la búsqueda de los valores sociales que deben ser tutelados mediante instrumentos jurídicos ${ }^{18}$.

15 Ibídem, p. 206

16 BARBERIS, M. El realismo jurídico europeo-continental. En: Enciclopedia de Filosofía y Teoría del Derecho [en línea]. México: Universidad Nacional Autónoma de México, 2015 [consultado 3 de sepbiembre de 2020], pp. 227-240. Disponible en: https://archivos.juridicas. unam.mx/www/bjv/libros/8/3875/9.pdf.

17 Olivecrona, K. Lenguaje jurídico y realidad [en línea]. México: Distribuciones Fontamara [fecha de consulta: 3 de septiembre de 2020]. Disponible en: https://teoriageneraldelderecho122028.files.wordpress.com/2010/09/lenguaje-juridico-y-realidad-karl-olivecrona.pdf. Aquí resultará especialmente importante tener en cuenta el lenguaje jurídico como una forma de influir en el comportamiento de los seres humanos. La forma en la que se expresan los hechos que acontecen entre las personas se convierte en un instrumento tanto de control social, como de comunicación social. En palabras del autor, la realidad "consiste en un cierto tipo de emplazamiento en el contexto social que depende de la reacción uniforme de la gente. [...] si se suprime esta reacción, las palabras realizativas se vuelven vacías".

18 Ibídem, p. 211. 
Será Alf Ross quien más adelante nos recuerde que el Derecho es un fenómeno de la realidad en la medida en que su contenido es un hecho histórico que varía de acuerdo con el tiempo y el lugar, que ha sido creado por el hombre y depende de factores externos de poder ${ }^{19}$. Para este autor, las normas se consideran vigentes cuando a ellas se adhiere una comunidad determinada, reconociéndolas como obligatorias. Aquí, el carácter intersubjetivo resulta trascendental dado que manifiesta la forma en la que las personas se relacionan con las normas comunes, de manera que el cúmulo de acciones individuales se constituye en un todo significativo ${ }^{20}$.

En la escuela realista italiana, Giovanni Tarello afirmaría que mientras que el legislador sólo produce enunciados y disposiciones, el juez es quien crea los significados (o normas) ${ }^{21}$. Su principal discípulo, Ricardo Guastini, apartándose en algo de su maestro, recurre a la teoría kelseniana del "marco" para mitigar la posición escéptica de su antecesor acerca de la interpretación ${ }^{22}$. Guastini afirma que las disposiciones no carecen de significado antes de la interpretación, existiendo un marco de significados (la Constitución y la ley), entre los que el intérprete debe elegir para producir la norma ${ }^{23}$. Si bien este autor exalta el poder interpretativo en cabeza de los jueces, será Comanducci quien destaque la relación funcional entre la interpretación judicial y la aplicación del Derecho. Así, para este último, es el juez quien "elige el significado de la disposición de la norma abstracta susceptible de ser aplicada en casos concretos" 24 .

Con relación al realismo jurídico francés, éste encuentra gran representación en la propuesta de Michel Troper, quien potencia el papel de los tribunales superiores constitucionales. Para este pensador, "una jerarquía normativa sólo es tal si es reconocida por los tribunales, [...] cuya discrecionalidad interpretativa es potencialmente ilimitada" 25 . En esta propuesta también se refleja el carácter jerárquico de la Constitución, la cual actúa como "máquina" de constricción en el ejercicio de las competencias gubernamentales y judiciales.

19 Ibídem, p. 212.

20 Torres, I. La trascendencia de los términos no referenciales en el lenguaje jurídico: los conceptos tu-tu. Ciencia Jurídica. 2015, 7. 141-154 [fecha de consulta: 3 de septiembre de 2020]. Disponible en: file:///Users/adminis/Downloads/Dialnet-LaTrascendenciaDeLosTerminosNoReferencialesEnElLen-5144760.pdf.

21 BARBERIS, M. El realismo jurídico europeo-continental. En: Enciclopedia de Filosofía y Teoría del Derecho [en línea]. México: Universidad Nacional Autónoma de México, 2015 [consultado el 3 de sepbiembre de 2020], pp. 227-240. Disponible en: https://archivos.juridicas. unam.mx/www/bjv/libros/8/3875/9.pdf.

22 Según Tarello, las normas pueden recibir cuantas interpretaciones sean posibles. Contrario a esto, Guastini retoma la idea de un marco o jerarquía superior que podría actuar como límite a la discrecionalidad judicial.

23 Ibídem, p. 232.

24 Ibídem, p. 233

25 Ibídem, pp. 133-134. 
Además de lo anterior y para los efectos de este escrito, vale tener en cuenta que fruto de los avances del realismo jurídico en sus diversas variantes, surge un campo de estudio conocido como "Derecho y Sociedad". Esta corriente, desarrollada principalmente en Estados Unidos en la segunda mitad del siglo Xx, propone una revaloración de la concepción del Derecho que guarde plena relación con su dimensión social y política. Tal y como lo recuerda Pezzetta ${ }^{26}$, el Derecho ya no sería entendido como un mero conjunto de normas y principios, sino como institución social, de comportamientos, de símbolos y rituales y como producto de los intereses de grupos políticos.

De la misma manera, los estudios críticos del Derecho (Critical Legal Studies) nacen en la década de los ochenta como herederos de realismo jurídico estadounidense. En palabras de Flórez ${ }^{27}$, dicho nicho de conocimiento y de acción política defiende que el Derecho es en esencia política -"law is politics"-, y por ello abordan el fenómeno jurídico como fenómeno político. $\mathrm{Al}$ igual que el realismo jurídico, los estudios críticos del derecho defienden las investigaciones de carácter inter y multidisciplinario trascendiendo de la metodología estructuralista a los estudios deconstructivistas ${ }^{28}$.

Una de las principales luchas emprendidas por el realismo jurídico, los estudios de Derecho y Sociedad y los Critical Legal Studies, ha sido la de renovar el formalismo jurídico, hacia interpretaciones críticas sobre el derecho en el que éste pueda reconocerse como campo que se desarrolla y completa a partir de su interacción con otros saberes, especialmente de las ciencias sociales.

Los Critical Legal Studies agregan otros dos aspectos determinantes a esta tarea emancipadora:

(1) En primer lugar, el reconocimiento de la "contradicción fundamental", esto es, aceptar que el Derecho no tiene una respuesta unívoca a todos los casos o problemas a los que se enfrenta, como si se tratase de aplicar normas generales, rígidas, precisas y abstractas en cada uno de ellos, sino que, contrario a esto, existen situaciones conflictivas en las que las que normas y principios, e incluso posturas morales y políticas, entran en conflicto y se hace necesario apelar a los objetivos sustantivos que se persigan en determinado contexto.

(2) El segundo aporte importante de los Critical Legal Studies consiste en tener en cuenta constructos teóricos eminentemente locales, sin pretender acudir a teorías generales aplicables a todos los contextos posibles ${ }^{29}$.

26 Pezzeta, S. Derecho y sociedad. Historia y presente de los herederos del realismo jurídico estadounidense. En: Frabra, J. \& Núñez, A. (coord.). Enciclopedia de filosofía y teoría del Derecho [en línea]. México: unam. 2015 [consultado 20 de febrero de 2020], 667-691. Disponible en: https://archivos.juridicas.unam.mx/www/bjv/libros/8/3875/21.pdf.

27 FLóREZ, L. La contradicción fundamental en el movimiento critical legal studies. Revista temas sociojurídicos, 2018, vol. 37 (74), 68-84 [consultado el 9 de agosto de 2019]. ISSN: 0120-8578.

28 Ibídem.

29 Ibídem, p. 81. 
De lo expuesto anteriormente, podríamos decir que el realismo jurídico se basa esencialmente en los siguientes postulados:

1. La necesidad de concentrarse en los hechos o el contexto en el que se crea el Derecho.

2. La exaltación del papel de los jueces en la interpretación de dichos hechos en la dinámica y evolución del Derecho.

3. La preocupación por cómo las formas e instituciones cumplen una determinada función en las etapas de desarrollo social.

4. La necesaria relación entre el Derecho y la sociedad para la comprensión de la realidad. Sólo así se puede entender qué es el Derecho, así como cuándo y quién lo crea y aplica.

5. La inminente relación entre el Derecho y otras ciencias del conocimiento, particularmente la Ciencia Política.

\section{A. Realismo jurídico transicional en Colombia}

Tal como lo propusimos en un inicio, a partir de las posturas destacadas del realismo jurídico es posible realizar un análisis de comprensión, legitimación e implementación de los mecanismos de justicia transicional en Colombia. Esto es así, si mantenemos la idea de que el Derecho se corresponde esencialmente con el contexto en el cual se crea y aplica, y con la interpretación que hacen los jueces de él, basados en los fines y necesidades sociales imperantes. Dichas consideraciones tienen que ver con la relación Derecho-sociedad.

Para comprender la justicia transicional en Colombia a partir del enfoque realista jurídico, es necesario apegarnos a dos postulados de esta teoría a saber: (1) el Derecho responde a los hechos y las necesidades sociales en un contexto determinado y (2) los jueces ocupan un papel protagónico en la adaptación del Derecho y las instituciones jurídicas a las necesidades sociopolíticas del momento.

Dentro de las diversas concepciones sobre la justicia transicional existen algunas que destacan la aplicación de estos postulados.

Según la Organización de las Naciones Unidas, la justicia transicional "abarca toda la variedad de procesos y mecanismos asociados con los intentos de una sociedad por resolver los problemas derivados de un pasado de abusos a gran escala, a fin de que los responsables rindan cuentas de sus actos, servir a la justicia y lograr la reconciliación" ${ }^{30}$. Esta misma definición fue recogida en la Ley 1448 de 2011, en la que se entiende por justicia transicional el

30 Naciones Unidas. Comité de Derechos Humanos. Conjunto de principios actualizados para la protección y promoción de los derechos humanos mediante la lucha contra la impunidad. E/CN.4/2005/102/Add.1 (8 de febrero de 2005). 
conjunto de procesos y mecanismos judiciales o extrajudiciales asociados con los intentos de la sociedad por garantizar la justicia, la verdad y la reparación integral a las víctimas del conflicto, además de las reformas institucionales que eviten la repetición de los hechos ${ }^{31}$.

De Greiff ${ }^{32}$, por su parte, menciona que las diferentes medidas de justicia transicional que se adopten en un país comparten dos fines mediatos y un fin último. Como fines "mediatos" encontramos el reconocimiento a las víctimas y la confianza cívica, mientras que el fin último de la justicia transicional es el fortalecimiento de la norma de derecho democrática. Este objetivo final tiene que ver esencialmente con el fortalecimiento de la democracia, cuestión que no se logra fácilmente, sino a través de la concreción de varios factores ${ }^{33}$ políticos, jurídicos y sociales. Por supuesto, estos objetivos deben ser evaluados a la luz del Estado social y democrático de Derecho en el que se define el rumbo jurídico-político del país. De manera que en este caso la justicia transicional también puede verse como un vehículo para la construcción de paz $^{34}$ como valor y derecho constitucional ${ }^{35}$.

Sobre los desafíos jurídicos en periodos de transición, Teitel destaca que los estados de derecho se enfrentan a distintas tensiones en momentos de transformaciones o cambios políticos y sociales. Entre esas tensiones se encuentran los cambios paradigmáticos en la idea sobre la justicia, la corrección y la continuidad jurídica ${ }^{36}$. Nuevamente, su planteamiento se realiza inductivamente, a través del análisis e interpretación de diversas experiencias de transición de la posguerra y otras más contemporáneas. Sobre la primera, la autora hace alusión al debate Hart-Fuller, que, entre otras consideraciones de importancia jurídica, enfrenta las teorías clásicas del positivismo y el derecho natural. La pregunta central en este caso gira en torno a la validez del Derecho alemán durante el régimen nazi, por un lado, y la propuesta de Fuller según la cual el Derecho sin corrección moral es derecho inválido ${ }^{37}$. Esta tensión tenía a su vez implicaciones en la pregunta sobre cuál es el Derecho aplica-

31 Ley 1448 de 2011. Por la cual se dictan medidas de atención, asistencia y reparación integral a las víctimas del conflicto armado interno y se dictan otras disposiciones. 10 de junio de 2011. D.O n. ${ }^{\circ} 48096$.

32 De Greiff, P. Algunas reflexiones acerca del desarrollo de la Justicia Transicional. Anuario de Derechos Humanos, 2011, (7), 17-39 [consultado el 2 de febrero de 2019]. Disponible en: https://corteidh.or.cr/tablas/r29408.pdf.

33 Ibídem.

34 RetTBERg, A. La construcción de paz bajo la lupa: una revisión de la actividad y de la literatura académica internacional. Estudios Políticos, 2013, vol. 42, 13-36 [consultado el 11 de septiembre de 2019]. Disponible en https://corteidh.or.cr/tablas/r31409.pdf.

35 Constitución Política de Colombia [Const.]. Preámbulo, artículo 22. 7 de julio de 1991 (Colombia).

36 Tertel, R. Justicia transicional. Traducido por M. J. Viana. $1^{\text {a }}$ ed. en castellano. Bogotá: Universidad Externado de Colombia, 2017. ISBN 978-958-772-760-9.

37 Ibídem, pp. 39-46. 
ble en y para la superación del régimen anterior. Discusión importante si se tiene en cuenta que desde el punto de vista teórico nos estamos preguntando cuál es el papel del Derecho en tiempos de transición. Una respuesta realista, aplicada al "Estado de derecho transicional", explicaría cómo encontrándonos en la fase de normalización de la justicia transicional ${ }^{38}$ aplicable al caso colombiano, las medidas de transición se implementan en un Estado que ha padecido graves y masivas violaciones a los derechos humanos aún bajo la tutela de "regímenes constitucionales democráticos".

Teitel va más allá, identificando el papel de las cortes constitucionales en tiempos de transición, dado su papel en la definición y aplicación del Derecho. De esta manera, la autora reconoce que los poderes judiciales enfrentaron un problema de equilibrio entre valores dominantes. En sus palabras, "el equilibrio transicional dependerá del distintivo legado histórico y político" 39 . Si esto es así, podríamos reconocer que la interpretación de los órganos judiciales, en este caso nuestra Corte Constitucional, tuvo un rol trascendental en la definición de los valores y derecho aplicable en cuanto a la adopción e implementación de las medidas de justicia transicional. Para ello, como se ha mencionado en diversas sentencias, tuvo que apelar a la ponderación de principios, y a lo que se podría denominar como una interpretación transformativa de los derechos a la justicia, a la paz y a la reparación de las víctimas en momentos de transición.

Por esta razón, se propone tener en cuenta tres aspectos de la configuración de la justicia transicional en Colombia que revelan una interpretación realista del Derecho ajustada al contexto nacional: (a) el papel de la Corte Constitucional en la adopción de medidas de transición, (2) la creación de la Jurisdicción Especial para la Paz y (3) la constitucionalización de la justicia transicional.

\section{El papel de la Corte Constitucional en}

la adopción de mecanismos de transición

La complejidad del conflicto en el país ${ }^{40}$ pasa por su prolongación en el tiempo, la multiplicidad de actores armados implicados, la participación del Estado en la implementación de políticas abusivas, las múltiples modalidades de violación a derechos humanos cometidas por los victimarios, los millones

38 IbARRa, A. Justicia Transicional: la relación Derecho-Poder en los momentos de transición. Revista de Derecho, 2016, (45), 237-261 [consultado el 4 de septiembre de 2020]. Disponible en: http://rcientificas.uninorte.edu.co/index.php/derecho/article/view/7176/7978.

39 Teitel, R. Justicia transicional. Traducido por M. J. Viana. $1^{\text {a }}$ ed. en castellano. Bogotá: Universidad Externado de Colombia, 2017. ISBN 978-958-772-760-9.

40 Melo, J. Historia Mínima de Colombia: La historia de un país que ha oscilado entre la guerra y la paz, la pobreza y el bienestar, el autoritarismo y la democracia. $1^{\mathrm{a}}$ ed. Madrid: Editorial Turner. 2017. ISBN: 978-84-16714-07-0. 
de víctimas dejadas a su paso y, más recientemente, las dificultades de implementación de los mecanismos de transición aunado al rearme de varios ex desmovilizados del proceso de paz entre el Gobierno y las FARC-EP.

El análisis de la configuración del modelo de justicia transicional en Colombia debe contemplar especialmente las decisiones que ha tomado la Corte Constitucional para la legitimar o no los mecanismos de transición propuestos por el Gobierno. De esta manera, son varias las decisiones judiciales del tribunal en las que se ha tratado de esclarecer la constitucionalidad de los instrumentos de transición implementados jurídicamente en el país. No es objeto de este artículo la realización de una línea jurisprudencial al respecto. Sin embargo, sí podemos destacar algunas sentencias que coinciden de alguna forma con los hitos de configuración del modelo nacional, y por tanto pueden resultar bastante significativas.

En 2006, por ejemplo, a través de la sentencia C-370 ${ }^{41}$, la Corte resolvió una demanda de inconstitucionalidad en contra de la Ley 975 de $2005^{42}$, conocida como "Ley de Justicia y Paz", incoada por un grupo de 105 ciudadanos actuando en nombre propio y en representación de diversas organizaciones, que cuestionaban la constitucionalidad de la ley, al señalar que la misma promovía un "sistema de impunidad" que no garantizaba los derechos de las víctimas.

Pese a que esta norma ha sido reconocida por varios autores como el primer instrumento jurídico para la justicia transicional en el país, en su sentencia la Corte advierte sobre el valor del control constitucional, aún en la evaluación de medidas legislativas que se presenten como instrumentos para alcanzar la paz. En ese sentido, el tribunal manifestó que

[...] el legislador puede diseñar los mecanismos que estime conducentes a lograr la paz, valorando las circunstancias específicas de cada contexto. Lo anterior no significa que esta amplia competencia del legislador carezca de límites constitucionales. Compete al juez constitucional identificar tales límites y hacerlos respetar, sin sacrificar ninguno de los elementos constitucionales en tensión y sin sustituir al legislador en el ejercicio de las competencias que le son propias.

La evaluación a cargo del tribunal constitucional no es menor, sobre todo si tenemos en cuenta que dicho análisis ha supuesto un ejercicio de ponderación entre principios y derechos constitucionalmente protegidos. En este sentido, la Corte expresó que el legislador, en aras de propiciar la desmovilización

41 Corte Constitucional de Colombia. Sentencia C-370 de 2006. M. P. Manuel José Cepeda Espinosa: 18 de mayo de 2006.

42 Ley 975 de 2005. Por la cual se dictan disposiciones para la reincorporación de miembros de grupos armados organizados al margen de la ley, que contribuyan de manera efectiva a la consecución de la paz nacional y se dictan otras disposiciones para acuerdos humanitarios. 25 de julio de 2005. D.O n. ${ }^{\circ} 45.980$. 
y reintegración de integrantes de grupos al margen de la ley, propuso una reforma al procedimiento penal, situación que supone un conflicto entre el derecho a la justicia, por un lado, y el derecho a la paz y reparación integral de las víctimas, por otro, todos reconocidos constitucionalmente y protegidos por instrumentos internacionales sobre la materia.

Otro de los elementos para tener en cuenta es que la Corte haya reconocido que el derecho a la paz estable y duradera que sustrae al país del conflicto armado interno supone ciertas restricciones al valor objetivo de la justicia. Esto es, en las condiciones del contexto colombiano se exige la toma de medidas jurídico-políticas que a todas luces afectan derechos y valores constitucionales. Resulta interesante que la adopción de la Ley 975 plantee un problema novedoso y es el de cómo ponderar la paz, máxime cuando la Constitución de 1991 le asignó una enorme trascendencia, quedando consignada en su preámbulo, dentro de los fines del Estado, como derecho fundamental, y como deber ciudadano. Dicha decisión judicial demuestra el importante papel legitimador llevado a cabo por la Corte Constitucional, al afirmar que la finalización del conflicto armado interno en el país y la garantía de la paz como derecho humano exigen la adopción de ciertas medidas jurídicas que limitan el ejercicio y la garantía de otros derechos de rango fundamental-constitucional.

Por su parte, por ejemplo en la sentencia C-579 de $2013^{43}$, a través de la cual el tribunal revisó la constitucionalidad del acto legislativo 01 de $2012^{44}$, más conocido como "marco jurídico para la paz", la Corte decidió que éste no sustituye los elementos definitorios de la Constitución Política. Contrario a esto, dijo:

[...] La comunidad internacional ha admitido la importancia de alcanzar la paz, permitiendo la celebración de acuerdos políticos de reconciliación con amplios grupos sociales, lo cual exige cierta flexibilidad a la hora de aplicar los principios que dominan el ejercicio de la función judicial sin desconocer las obligaciones internacionales de los estados en el compromiso universal de respeto a la dignidad y a los derechos humanos, sino permitiendo que se cumplan de manera especial.

En este sentido, se retoma el postulado del realismo jurídico que manifiesta que el Derecho debe medirse según su capacidad de realización de fines humanos y sociales, al tiempo que se afirma, como lo postularon algunos autores

43 Corte Constitucional de Colombia. Sentencia C-579 de 2013. M.P. Jorge Ignacio Pretelt Chaljub: 28 de agosto de 2013.

44 Acto Legislativo 01 de 2012. Por medio del cual se establecen instrumentos jurídicos de justicia transicional en el marco del artículo 22 de la Constitución Política y se dictan otras disposiciones. 31 de julio de 2012. D. O. n. ${ }^{\circ}$ 48.508. Recordemos que esta es la norma jurídica que avala en un primer momento el proceso de negociación entre el gobierno del entonces presidente Santos y la guerrilla de las FARC. 
de la escuela escandinava, que los jueces interpretan el derecho de acuerdo a un marco. Dicho marco está representado esencialmente en la Constitución Política, a través de la cual se determinan los principios, valores y derechos perseguidos en el Estado democrático.

Más adelante, a través de la sentencia C-017 de $2018^{45}$, la Corte reitera su jurisprudencia, en el sentido de establecer que "la justicia transicional constituye un conjunto de mecanismos que no obedecen a fórmulas rígidas, sino que deben atender las características de cada contexto histórico, geográfico, político y social, así como a las particularidades de cada momento de transición". Queda claro que los parámetros de control de las normas para la terminación del conflicto armado y la construcción de una paz estable y duradera están representados en la Constitución misma, las experiencias comparadas, el margen de configuración normativo del legislador extraordinario para la paz y los estándares internacionales y de órganos internacionales sobre derechos humanos. Esto configura, según el tribunal, un estándar de control flexible previsto para el análisis de constitucionalidad de los mecanismos y medidas de justicia transicional creados en el país.

\section{La Jurisdicción Especial para la Paz (JEP)}

El Acuerdo para la terminación del conflicto con las FARC abrió un espacio muy importante para la creación de mecanismos de transición sin precedentes en la historia nacional. Al funcionamiento articulado y sistémico de dichos mecanismos se le denominó Sistema Integral de Verdad, Justicia, Reparación y No Repetición, diseñado bajo el principio de reconocimiento de las víctimas como ciudadanos con derechos ${ }^{46}$. Dichos mecanismos incluyen una nueva institucionalidad conformada por la Comisión para el Esclarecimiento de la Verdad, la Unidad de Búsqueda de Personas dadas por Desaparecidas y la Jurisdicción Especial para la Paz.

La creación de esta última, especialmente, refleja otra de las expresiones del realismo jurídico transicional en Colombia. Dicho organismo jurisdiccional, legalizado a través de diversos instrumentos jurídicos ${ }^{47}$, tiene la labor de

45 Corte Constitucional de Colombia. Sentencia C-017 de 2018. M. P. Diana Fajardo Rivera: 21 de marzo de 2018. Vale recordar que se trata de una sentencia a través de la cual la Corte Constitucional hace un control automático de constitucionalidad del Decreto Ley 588 de 2017, por el cual se organiza la Comisión para el Esclarecimiento de la Verdad, la Convivencia y la No Repetición.

46 GOBIERNO NACIONAL y FARC-EP. Acuerdo final para la terminación del conflicto armado y la construcción de una paz estable y duradera [en línea], 24 de noviembre de 2016. Disponible en: https://www.jep.gov.co/Marco\%20Normativo/Normativa_v2/01\%20ACUERDOS/N01.pdf.

47 Acto Legislativo 01 de 2017. Por medio del cual se crea un título de disposiciones transitorias de la Constitución para la terminación del conflicto armado y la construcción de una paz estable y duradera y se dictan otras disposiciones, 4 de abril de 2017. D. O. n. ${ }^{\circ} 50.196$. Artículo transitorio 5. 
satisfacer el derecho de las víctimas a la justicia, ofrecer verdad a la sociedad colombiana y contribuir al logro de la paz en el país, convirtiéndose en una institución fundamental para reconocer el papel del Derecho en tiempos de transición.

La JEP cuenta con un régimen legal propio ${ }^{48}$, y con capacidad de conocer de forma preferente y exclusiva las conductas punibles relacionadas con el conflicto armado interno cometidas con anterioridad al $1 .^{\circ}$ de diciembre de $2016^{49}$ por parte de miembros de la fuerza pública o integrantes de grupos al margen de la ley.

En términos de experiencias comparadas de justicia en periodos de transición, la JEP es un organismo sui generis sin antecedentes internacionales ${ }^{50}$. Este organismo nace como un ente judicial de carácter especial, con funciones temporales, y orientado bajo el paradigma de la justicia restaurativa, es decir, privilegiando "la armonía en el restablecimiento de relaciones de la sociedad, la restauración del daño causado y la garantía de los derechos de las futuras generaciones"

En su último informe sobre la situación de los derechos humanos en Colombia, el alto comisionado de las Naciones Unidas destaca el avance en la implementación de las medidas de justicia transicional, haciendo un énfasis especial en la posibilidad de participación de las víctimas en el proceso y la presencia territorial con que se ha legitimado su desarrollo ${ }^{52}$. Del mismo modo, sobre el funcionamiento de la JEP mediante el proceso de priorización y selección de casos, vale recordar que hasta el momento se han adelantado siete macrocasos así: (1) retención ilegal de personas, (2) situación de derechos humanos en Tumaco, Ricaurte y Barbacoas (Nariño), (3) muertes ilegítimamente presentadas como bajas en combate por parte del Estado, (4) situación humanitaria en algunos municipios de Antioquia y Chocó, (5) situación humanitaria en algunos municipios del Cauca, (6) victimización de miembros de la Unión Patriótica y (7) reclutamiento y utilización de niñas y niños en

48 Ley 1957 de 2019. Estatutaria de la Administración de Justicia en la Jurisdicción Especial para la Paz, 6 de junio de 2019. D. O. n. ${ }^{\circ} 50.976$

49 Ibídem, artículo 8. Además de esto, vale resaltar que la tanto el Acuerdo como la ley estatutaria han determinado que el Sistema Integral se rija no sólo por las leyes constitucionales, sino en virtud de los estándares internacionales de derechos humanos y el derecho internacional humanitario, lo cual se puede considerar como una expresión del enfoque idealista de cara a la consideración de la justicia transicional como un campo que se ha construido internacionalmente.

50 Medina, C. La Jurisdicción Especial para la paz (JEP): claridades e incertidumbres de un modelo innovador de justicia transicional. Cuadernos de Estrategia [en línea]. 2017, (189), 221-232 [fecha de consulta: 11 de noviembre de 2019]. ISSN 1697-6924.

51 Ley 1957 de 2019. Estatutaria de la Administración de Justicia en la Jurisdicción Especial para la Paz. 6 de junio de 2019. D. O. n. ${ }^{\circ} 50.976$.

52 Naciones Unidas. Consejo de Derechos Humanos. Informe anual del Alto Comisionado de Naciones Unidas para los Derechos Humanos. Situación de los derechos humanos en Colombia. A/HRC/43/3Add.3 (26 de febrero de 2020). 
el conflicto armado colombiano ${ }^{53}$. Dicha cuestión da cuenta del enfoque diferenciado con que trabaja la jurisdicción, a través de la priorización de las necesidades de las víctimas que han sufrido de manera desproporcionada y diferenciada los efectos de las graves infracciones y violaciones cometidas con ocasión del conflicto ${ }^{54}$.

\section{Constitucionalización de la Justicia Transicional en Colombia}

Tal como lo afirma Hernando Valencia, el constitucionalismo colombiano debe ser analizado a través de un enfoque crítico que combine herramientas históricas y jurídicas, y entiendan el papel del derecho en la evolución del discurso constitucional ${ }^{55}$.

De esta manera, es de comprender que la Constitución colombiana se ha reformado en contextos de conflicto de fuerzas y discursos que han enmarcado cada codificación y cada enmienda ${ }^{56}$. Así, si bien en la historia del constitucionalismo colombiano la Carta Política es vista como un instrumento de gobierno para imponer un orden político determinado o consolidar un aparato institucional capaz de controlar la totalidad de la población ${ }^{57}$, las reformas constitucionales que incluyen normas transitorias para la terminación del conflicto y la construcción de paz, deben ser vistas como medios y fines para que la sociedad y las instituciones colombianas se reconstruyan a partir de un ejercicio democrático.

El proceso de constitucionalización de la justicia transicional no ha estado exento de dificultades. Prueba de ello han sido las variadas demandas de inconstitucionalidad presentadas en contra del marco legal que la crea y la regula. No obstante esto, como se mencionó anteriormente, la Corte Constitucional, enfrentada incluso a la ponderación de principios y derechos constitucionales, ha reconocido la importancia de la implementación de las medidas de transición, que no sólo avalan la negociación para el fin del conflicto surtida entre el gobierno y las FARC, sino que reconocen especialmente la necesidad de reparar integralmente a las víctimas de la guerra en el país, y responder a los estándares internacionales de derechos humanos en favor de la sociedad colombiana en general y los directamente afectados por el conflicto en particular ${ }^{58}$.

53 Jurisdicción Especial para la Paz [en línea] [fecha de consulta: 11/11/2019]. Disponible en: https://www.jep.gov.co/Infografas/conozcalajep.pdf.

54 Ley 1957 de 2019. Estatutaria de la Administración de Justicia en la Jurisdicción Especial para la Paz. 6 de junio de 2019. D. O. n. ${ }^{\circ} 50.976$.

55 Valencia, H. Cartas de Batalla. Una crítica del constitucionalismo colombiano. Bogotá: Editorial Panamericana, 2018. ISBN: 978-958-30-3477-0.

56 Ibídem. p. 31.

57 Ibídem. p. 53.

58 Ruiz Rico, G. Un diagnóstico constitucional de la justicia transicional. Anuario Iberoamericano de Justicia Constitucional [en línea]. 2018, (22). 133-164 [fecha de consulta: 7 de julio de 2019]. ISSN 1138-4824. 
Por otro lado, tal como lo reconoce Gerardo Ruiz ${ }^{59}$, las modificaciones constitucionales a que ha dado lugar la implementación del Acuerdo de Paz potencia la protección jurídica del derecho a la paz como derecho público subjetivo accionable frente al Estado. De esta manera, la primera modificación constitucional relativa a la terminación del conflicto en el país fue el acto legislativo 01 de 2012, también llamado "marco jurídico para la paz", además del acto legislativo 01 de 2017 a través del cual se crea un nuevo título transitorio a la norma constitucional con regulación expresa para la terminación del conflicto armado interno y la construcción de una paz estable y duradera. Dicho título contempla esencialmente la creación de un Sistema Integral de Justicia, Verdad, Reparación y No Repetición, incluyendo medidas imprescindibles para la atención y reparación a víctimas del conflicto armado interno.

En total, vale destacar que la constitucionalización de la justicia transicional ha sido determinada en virtud de su correspondencia con los pilares de la Carta y los instrumentos convencionales sobre derechos humanos y derecho internacional humanitario ratificados por el Estado colombiano. Esto, sumado a las condiciones destacadas por el tribunal constitucional para la aplicación legítima de tales medidas. Entre estas podríamos mencionar: la objetividad en la investigación, el juzgamiento y la sanción a los responsables de la comisión de delitos graves contra los derechos humanos, la desmovilización efectiva de miembros del grupo ilegal, la reparación integral a las víctimas $\mathrm{y}$, en total, el cumplimiento de todos los principios y garantías que orientan el funcionamiento del sistema integral creado.

De esta manera, la configuración del modelo de justicia transicional en Colombia da muestras de la aplicación del enfoque realista jurídico. En primer lugar, dada la importancia de la Corte Constitucional, al adoptar una clara interpretación pro víctima, modelando y dotando de contenido a los instrumentos de transición ${ }^{60}$, y defendiendo la constitucionalidad de los distintos actos legislativos con los que se protegen las medidas adoptadas en el Acuerdo de La Habana. Para Abuchabe ${ }^{61}$, a través de los fallos de la Corte se ha creado un derecho constitucional transicional, del que hacen parte distintos estándares que establecen el alcance y los límites de los mecanismos adoptados y su implementación. En segundo lugar, reconociendo la creación judicial del Derecho $^{62}$, al resaltarse la importancia tanto del tribunal constitucional, como de la recién creada jurisdicción para la paz, en aras de administrar justicia para la implementación de las medidas de justicia transicional creadas.

59 Ibídem, p. 148.

60 AвuchaIbe, H. La justicia transicional del posacuerdo con las FARC-EP. Revista Ópera. 2017, 20, 129-153 [fecha de consulta: 12 de diciembre de 2019]. ISSN 1657-8651.

61 Ibídem.

62 BARBERIs, M. Para una teoría realmente realista del Derecho. Revista Revus [en línea]. 2016, 29, 15-23. ISSN 1855-7112. 
El realismo político es una corriente filosófica emparentada con concepciones pesimistas y escépticas sobre la política y las relaciones de poder. Algunos autores entienden el realismo como una actitud cínica dada su reserva y desconfianza frente a la proclamación de elevados ideales de paz y de justicia, así como por su rechazo a una política deontológica. En ese sentido, el único medio para la conservación de la comunidad política es la guerra como derecho intrínseco de los Estados ${ }^{63}$. Maquiavelo y Tucídides suelen identificarse como los representantes más destacados de esta ala del realismo.

No obstante lo anterior, encontramos también corrientes de realismo político que si bien aceptan la limitación a la hora de explicar y juzgar el fenómeno político a la luz de principios éticos, promueven una visión realista moderada al hacer un llamado al equilibrio de intereses, la conciliación de conflictos y persecución de objetivos sociales desde la política.

Según Morgenthau ${ }^{64}$, el realismo político es una escuela de la historia del pensamiento moderno que afirma que

[...] el mundo, imperfecto desde un punto de vista racional, es el resultado de fuerzas inherentes a la naturaleza humana. Para mejorar al mundo, se debe trabajar con estas fuerzas y no contra ellas. Al ser el nuestro un mundo de intereses opuestos y conflictivos, los principios morales nunca pueden realizarse plenamente. Pero al menos podemos acercarnos a ellos mediante el siempre temporario equilibrio de intereses y la siempre precaria conciliación de los conflictos.

En esa línea, "el realismo político no requiere ni condona la indiferencia hacia los ideales políticos o los principios morales, pero sí reclama una nítida diferenciación entre lo deseable y lo posible, entre lo que es deseable en todas partes y en cualquier tiempo y lo que es posible bajo circunstancias concretas de tiempo y lugar" ${ }^{\prime 65}$.

De ahí que podamos afirmar que el realismo político se construye a partir del estudio de la realidad factual, atendiendo a los hechos que son empíricamente verificables, y que se encuentran en el pasado y en la actualidad.

Morgenthau también reconocería la existencia de imperativos éticos universales. No obstante, afirma que éstos no pueden imponerse de manera mecánica

63 CABRERA, E. Una tipología de realismo político. Aproximación desde el análisis conceptual. Signos filosóficos [en línea]. 2014, XVI (31), 125-155 [fecha de consulta: 31 de marzo de 2019]. ISSN 1665-1324.

64 Citado en CARvajal, L. Morgenthau: ¿el Maquiavelo de la política internacional? Oasis. 2007, (12), 253-269 [fecha de consulta: 4 de abril de 2019]. Disponible en: https://revistas. uexternado.edu.co/index.php/oasis/article/view/2422.

65 Oro, L. En torno a la noción de realismo político. Revista enfoques: ciencia política y administración pública. 2009, vol. 7 (10), 15-46 [fecha de consulta: 2 de abril de 2019]. ISSN 0718-0241. 
al mundo político, sino que deben ser aplicados de manera flexible a la realidad, atendiendo a circunstancias específicas ${ }^{66}$. En este sentido, los principios morales universales no pueden ser aplicados en su formulación universal abstracta, sino que deben ser filtrados a través de las circunstancias concretas.

Otro de los aportes de Morgenthau al realismo político será la exaltación de la "prudencia política" como la mayor virtud del político. Dicha prudencia supone la existencia de "tres habilidades: la capacidad para sopesar diferentes bienes, la propensión a ponderar las circunstancias, y la disposición para rehuir a las soluciones que son idealmente perfectas. La primera es indispensable para resolver los dilemas que contraponen a aquellos valores que son igualmente dignos, pero que en determinadas circunstancias son incompatibles ( $v . g r$. , seguridad versus libertad). La segunda permite discernir cuál es el mejor momento para actuar. La tercera desdeña la solución óptima y opta por el mal menor. ¿Por qué? Porque la fórmula idealmente perfecta no siempre es la más viable ni razonable por los costos que su aplicación conlleva" ${ }^{67}$.

\section{A. Realismo político transicional en Colombia}

No cabe duda de que la elección de la ruta y los mecanismos para la terminación de los conflictos armados internos depende sustancialmente de las decisiones gubernamentales de cada momento histórico. Por esta razón se afirma que las condiciones políticas, sociales y jurídicas del país determinan lo que se puede hacer y cuándo ${ }^{68}$.

Desde la década de los ochenta, el país venía optando por una salida negociada al conflicto ${ }^{69}$, lo cual incluía el reconocimiento político de los grupos insurgentes. Dicha intención estuvo avalada por instrumentos legislativos que permitieron adelantar negociaciones, suscribir acuerdos con organizaciones armadas al margen de la ley, promover la participación política de excombatientes y suspender la ejecución de medidas penales contra los miembros de éstos grupos bajo determinadas condiciones ${ }^{70}$. Todas estas, medidas que se

66 Ibídem, p. 30.

67 Ibídem, p. 34.

68 International Center of Transitional Justice. ¿Qué es la justicia transicional? [en línea] [fecha de consulta: 8 de mayo de 2019]. Disponible en: https://www.ictj.org/es/que-es-la-justiciatransicional.

69 Melo, J. Historia Mínima de Colombia: La historia de un país que ha oscilado entre la guerra y la paz, la pobreza y el bienestar, el autoritarismo y la democracia. $1^{\text {a }}$ ed. Madrid: Editorial Turner. 2017. ISBN: 978-84-16714-07-0. El autor menciona cómo el gobierno de Belisario Betancourt rompió las políticas nacionales anteriores defendiendo decididamente los procesos de paz en Latinoamérica, y promoviendo los Acuerdos de La Uribe, a través de los cuales se logró la desmovilización de varios grupos guerrilleros.

70 Ley 418 de 1997. Por la cual se consagran unos instrumentos para la búsqueda de la convivencia, la eficacia de la justicia, y se dictan otras disposiciones, 26 de diciembre de 1996. D. O. n. ${ }^{\circ} 43.201$. 
hicieron posibles de acuerdo a las circunstancias de tiempo y lugar propias de cada periodo gubernamental y la postura política frente a la paz y las formas de superar el conflicto. De esta manera, parecía que las medidas propuestas desde el ejecutivo permitirían que las estructuras de poder cedieran para allanar el camino hacia la democratización del Estado. En ese sentido, la redistribución de derechos, la representación y la participación en espacios de decisión sobre lo público serían signos de la transición política ${ }^{71}$.

El cúmulo de intentos fallidos por superar definitivamente el conflicto armado con todas las guerrillas existentes, que coincide con el establecimiento de estándares internacionales sobre justicia transicional, marca diferentes hitos históricos en los que se configura el modelo de justicia transicional nacional, haciendo evidentes algunas tensiones políticas que han condicionado la adopción e implementación de mecanismos de transición.

\section{La política de la Seguridad Democrática}

La intención política de llegar a una salida negociada al conflicto con los grupos guerrilleros que se había gestado desde los ochenta se deja atrás con la llegada al poder de Álvaro Uribe Vélez. Su gobierno presidencial (20022010) desconoció la existencia del conflicto armado interno, afirmando que la lucha contra organizaciones criminales y actores terroristas impedía por completo el reconocimiento político de los grupos guerrilleros, y con ello la posibilidad de una salida negociada al conflicto. Así, sus planes de gobierno, y la aceptación social de ellos, muestran la emergencia y consolidación de un discurso político hegemónico ${ }^{72}$ basado en la política de Seguridad Democrática. Esta incluía el fortalecimiento de la fuerza pública, la recuperación del control del territorio y la intervención militar en zonas afectas por el conflicto, sin descontar el apoyo a grupos paramilitares, que serían otro actor indiscutible de la guerra interna ${ }^{73}$. Pese a que desde el realismo político se ponen en cuestión los sesgos ideológicos que afectan la percepción de la realidad ${ }^{74}$, la política de la Seguridad Democrática reforzó la imagen de la insurgencia como la del enemigo u adversario que se debe aniquilar, encar-

71 Teitel, R. Justicia transicional. Traducido por M.J. Viana. $1^{\text {a }}$ ed. en castellano. Bogotá: Universidad Externado de Colombia, 2017. ISBN 978-958-772-760-9.

72 Gómez, G. Justicia transicional en disputa: Una perspectiva constructivista sobre las luchas por la verdad, la justicia y la reparación en Colombia, 2002-2012. $1^{\text {a }}$ ed. Medellín: Universidad de Antioquia, 2014. ISBN 978-958-714-615-8.

73 Departamento Nacional de Planeación. Plan Nacional de Desarrollo 2002-2006, Hacia un Estado Comunitario [en línea] [fecha de consulta: 10 de junio de 2019]. Disponible en: https://colaboracion.dnp.gov.co/cdt/pnd/pnd.pdf.

74 ORO. L. En torno a la noción de realismo político. Revista enfoques: ciencia política y administración pública [en línea]. 2009, vol. 7 (10), 15-46 [fecha de consulta: 2 de abril de 2019]. ISSN 0718-0241. 
celar, deslegitimar o minimizar ${ }^{75}$. La emergencia de la política de la guerra se debió en buena medida a la deslegitimación de los intentos frustrados de paz con las guerrillas. En palabras de Gómez, "de acuerdo con esta nueva forma de ver la realidad política colombiana, se construyó, además de una forma de definir el conflicto político, un conjunto de imaginarios sobre la división entre amigos y enemigos".

Esto permitió que el Derecho fuera utilizado en función del discurso de seguridad y como instrumento de la lucha política, reduciendo así la autonomía relativa de las racionalidades ética y jurídica como límites al poder ${ }^{76}$. Prueba de lo anterior es la expedición de la Ley 975 de 2005, más conocida como "Ley de Justicia y Paz", la cual se convierte en un hito legislativo en materia de justicia transicional. Como se ha sostenido en diversas oportunidades, sería la primera vez que en el país se reconocieran jurídicamente los derechos de las víctimas a la justicia, la verdad, la reparación y la no repetición ${ }^{77}$ a ser atendidos en virtud de un proceso de negociación y desmovilización de los grupos paramilitares. Dicho "avance" normativo, que proponía la implementación de medidas de transición no se preocupó por garantizar efectivamente los derechos de las víctimas, llegando incluso a incurrir en acciones de revictimización a la población afectada por el conflicto.

Lo anterior tiene que ver con lo que Uprimny y Saffón han entendido como la justicia transicional discursiva, esto es, la interpretación de la justicia de transición de acuerdo a los intereses de los autores que la usan ${ }^{78}$. Así, el discurso de la justicia transicional en el gobierno de Álvaro Uribe habría servido para manipular el concepto, fortalecer la impunidad a favor de las autodefensas y perpetuar las relaciones desiguales de poder entre víctimas y victimarios ${ }^{79}$.

Prueba de ello sería la extradición de los máximos responsables de paramilitarismo hacia Estados Unidos. Esta, que fue una decisión política del entonces presidente Uribe, comprometió significativamente las obligaciones con la verdad plena y la no repetición que les asiste a las víctimas del conflicto y a la sociedad colombiana en general. Asistimos al condicionamiento de la aplicación efectiva de mecanismos de transición, en virtud de estrategias

75 Chaparro, A. Acordar la paz en Colombia o "la cosa misma" de la filosofía. Estudios filosóficos [en línea]. 2018, (57), 35-57. ISSN 0121-3628.D.

76 Gómez, G. Justicia transicional en disputa: Una perspectiva constructivista sobre las luchas por la verdad, la justicia y la reparación en Colombia, 2002-2012. 1ª ed. Medellín: Universidad de Antioquia, 2014. ISBN 978-958-714-615-8.

77 Rúa, C. Los momentos de la justicia transicional en Colombia. Revista de Derecho [en línea]. 2015, (43), 71-109 [fecha de consulta: 8 de julio de 2019]. ISSN 0121-8697.

78 Uprimny, R. y SAFFon, M. Usos y abusos de la justicia transicional en Colombia. Anuario de Derechos Humanos. 2008, (4), 165-195 [fecha de consulta: 8 de julio de 2019]. Disponible en: https://revistas.uchile.cl/index.php/ADH/article/view/13511/13777.

79 Ibídem, p. 176. 
políticas de obstaculización a la justicia ${ }^{80}$. Cuestión que vemos reflejada en el debate actual sobre la solicitud de extradición de Salvatore Mancuso, quien tiene vigentes dos medidas de aseguramiento dictadas en la jurisdicción de Justicia y Paz, y sobre las que el acusado aceptó responsabilidad de manera incondicional como máximo comandante de las Autodefensas Unidas de Colombia $^{81}$. Las órdenes de captura internacional fueron libradas por la Sala de Justicia y Paz del Tribunal Superior de Barranquilla, y remitidas a la Dirección de Asuntos Internacionales del Ministerio de Justicia y del Derecho. En comunicado a la opinión pública, el Gobierno manifiesta que ha cumplido con todas las obligaciones en el trámite de solicitud de extradición ante el Departamento de Estado de los Estados Unidos, el cual sigue adelantando el estudio de ellas ${ }^{82}$. A todas luces, estas decisiones y gestiones revelan la ausencia de medidas administrativas transicionales, imposibilitando cualquier intento de transformación política afín a los ideales constitucionales que representan un posible paso hacía un Estado pacífico y democrático.

\section{El reconocimiento político de las víctimas del conflicto armado interno}

Más por la línea de realismo moderado, el reconocimiento político de las víctimas vislumbra una respuesta ética ante la complejidad del conflicto interno, sus consecuencias y las oportunidades para atender las graves y masivas violaciones de derechos humanos dejadas a su paso.

Así, bajo la presidencia de Juan Manuel Santos (2010-2018), se llevó a cabo una ruptura con el discurso oficial del gobierno de Uribe, adoptando legalmente una política de asistencia, atención, protección y reparación a las víctimas de violaciones manifiestas a los derechos humanos y el derecho internacional humanitario ${ }^{83}$. De manera que a través de la Ley 1448 de 2011 se crean mecanismos excepcionales para reparar y atender a las víctimas

80 Pese a que Salvatore Mancuso presentó solicitud de sometimiento a la JEP, la Sala de Reconocimiento de Verdad y Responsabilidad de dicha jurisdicción la rechazó argumentando que el peticionario no puede ser reconocido como tercero civil colaborador o financiador del paramilitarismo, dado su rol de miembro orgánico de la estructura criminal, en desarrollo de una función continua de combate. Jurisdicción Especial para la Paz [en línea] [fecha de consulta: 4 de septiembre de 2020]. Disponible en https://www.jep.gov.co/Sala-de-Prensa/Paginas/La-JEPrechaza-sometimiento-de-Salvatore-Mancuso.aspx

81 Rama Judicial, República de Colombia [en línea] [fecha de consulta: 4 de septiembre de 2020]. Disponible en: https://www.ramajudicial.gov.co/web/sala-de-justicia-y-paz-tribunalsuperior-de-barranquilla/-/sobre-la-extradicion-del-postulado-salvatore-mancuso-gomez-la-salade-justicia-y-paz-del-tribunal-superior-de-barranquilla-por-ser-un-tema-de-interes-

82 Oficina del Alto Comisionado para la Paz [en línea] [fecha de consulta: 4 de septiembre de 2020]. Disponible en: http://www.altocomisionadoparalapaz.gov.co/Documents/Comunicadoagosto.pdf.

83 Exposición de motivos de la Ley 1448 de 2011 presentada el 27 de septiembre de 2010 por parte del Ministerio del Interior y de Justicia a la Cámara de Representantes. Recuperado de https://es.slideshare.net/accionsocial/proyecto-de-ley-de-vctimas, p. 1. 
como única forma de materializar efectivamente la justicia de transición. Dicho instrumento legal dejó en evidencia que la garantía de los derechos de las víctimas sólo sería posible a través de la articulación de procesos institucionales y la coordinación de los entes del Estado ${ }^{84}$.

Dentro de la institucionalidad creada por esta ley se encuentran la Unidad de Restitución de Tierras, el Centro de la Memoria Histórica y la Unidad Administrativa Especial para la Atención y Reparación Integral a las Víctimas. Éstas, junto con otras entidades y programas nacionales conformaron un sistema nacional ${ }^{85}$ para formular e implementar la política integral de satisfacción de los derechos de las víctimas del conflicto.

En materia de legitimidad, esta postura no sólo tendría consecuencias político-jurídicas en términos del reconocimiento de los derechos de las víctimas y la sociedad en general, sino que abonaría el camino para el inicio de las conversaciones exploratorias con la exguerrilla de las FARC-EP, asî como el acompañamiento de la comunidad internacional en dicho empeño.

En otras palabras, desde el punto de vista político, el Estado se asume como sujeto de obligaciones jurídicas y políticas tanto en el plano nacional como en el internacional. La idea de la soberanía y el ejercicio del poder podrían entenderse acá no como un asunto del uso de la fuerza, sino como una cuestión de responsabilidad con la superación de un pasado de violencia y confrontación armada.

\section{La negociación con la guerrilla de las FARC-EP}

Sin duda alguna, el proceso de paz llevado a cabo con la guerrilla de las FARC reviste un carácter esencialmente político. Las partes en la negociación contaron con un amplio conjunto de herramientas para alcanzar el cese de las hostilidades y la elección de medidas de transición ajustadas a las necesidades y la experiencia nacionales.

Desde el enfoque realista político, esta realidad muestra la necesidad de ponderar diferentes bienes y circunstancias de dos de los actores implicados en el conflicto armado interno en el país, pero también la consideración de las víctimas del conflicto como las principales afectadas en tantos años de confrontación armada. "Se trató de aceptar alternativas concretas a los límites históricos de nuestra democracia, pero también la potencia de la renovación y la promesa de transformación que conlleva el respeto de las diferencias" $\$ 6$.

84 Ibídem, p. 3

85 Ley 1448 de 2011. Por la cual se dictan medidas de atención, asistencia y reparación integral a las víctimas del conflicto armado interno y se dictan otras disposiciones, 10 de junio de 2011. D.O n. ${ }^{\circ} 48096$.

86 Chaparro, A. Acordar la paz en Colombia o "la cosa misma" de la filosofía. Estudios filosóficos [en línea]. 2018, (57), 35-57. ISSN 0121-3628. 
Fiel a la concepción de la paz como deber estatal, el Acuerdo y su implementación se protegieron a través de un Procedimiento Legislativo Especial ${ }^{87}$. Esto otorgó al Gobierno nacional la facultad exclusiva para proponer proyectos de ley y actos legislativos, así como expedir decretos que desarrollaran lo acordado ${ }^{88}$.

Del mismo modo, se creó toda una institucionalidad para la garantía de los derechos de las víctimas ${ }^{89}$, de tal forma que es al Sistema Integral de Justicia, Verdad, Reparación y No Repetición (SIVJRNR) ${ }^{90}$, a través de sus diferentes organismos, a quien le corresponde el reconocimiento de las víctimas, la verdad, la responsabilidad y la reparación integral.

Además, como forma de anticiparse a los cambios gubernamentales que habían imposibilitado la salida negociada al conflicto, el Gobierno decretó que "las instituciones y autoridades del Estado tienen la obligación de cumplir de buena fe con lo establecido en el Acuerdo Final" "91 determinando que dicho compromiso debe ser cumplido hasta la finalización de tres periodos presidenciales completos posteriores a su firma.

Dichas consideraciones nos llevan a reconocer los condicionantes políticos que han rodeado la configuración del modelo de justicia transicional, al menos en los últimos tres periodos presidenciales desde 2002 hasta el año 2018 en lo que a los lineamientos sobre la política de paz respecta. Como se vio, la ejecución de dichas políticas ha dependido del diseño e implementación de instrumentos y procesos jurídicos que dan cuenta de la intersección e interdependencia entre diversos intereses, límites y miradas a la proposición y aprobación de los mecanismos de transición adoptados. En otras palabras, nos muestra el papel de la política en tiempos de transición.

87 Acto Legislativo 01 de 2016. Por medio del cual se establecen instrumentos jurídicos para facilitar y asegurar la implementación y el desarrollo normativo del acuerdo final para la terminación del conflicto y la construcción de una paz estable y duradera. 7 de julio de 2016. D. O. n. ${ }^{\circ}$ 49.927. Según este, el "Procedimiento Legislativo Especial para la Paz" tuvo con fin último agilizar y garantizar la implementación del Acuerdo a través de un proceso excepcional y transitorio por un periodo de seis meses, prorrogables por otros seis bajo comunicación formal del gobierno al Congreso de la República.

88 Dichas competencias de carácter legislativo, suponen que el ejecutivo concurre con el Congreso de la República en la producción de normas para la implementación del Acuerdo de Paz, claro está, de manera excepcional y transitoria.

89 Corte Constitucional de Colombia. Sentencia C-017 de 2018. M. P. Diana Fajardo Rivera: 21 de marzo de 2018.

90 Acto Legislativo 01 de 2017, artículo transitorio 1, parágrafo 2, regulado por el Acto Legislativo 01 de 2016, artículo 3 que establece el Plan de Inversiones para la Paz. Dicha disposición compromete al gobierno nacional durante los próximos veinte años a incluir en el Plan Plurianual de Inversiones del Plan Nacional de Desarrollo un componente específico para la paz, priorizando las entidades territoriales más afectadas por el conflicto, la pobreza, las economías ilegales y la debilidad institucional.

91 Acto Legislativo 01 de 2017. Por medio del cual se crea un título de disposiciones transitorias de la Constitución para la terminación del conflicto armado y la construcción de una paz estable y duradera y se dictan otras disposiciones. 4 de abril de 2017. D. O. n. ${ }^{\circ} 50.196$. 


\section{La llegada al poder de Iván Duque Márquez}

La llegada al poder de Iván Duque Márquez es prueba de que en Colombia no ha habido una verdadera transición política. Las experiencias de justicia transicional comparadas se representan esencialmente en la transición de periodos dictatoriales, de guerras civiles o de confrontación armada, hacia el fortalecimiento de escenarios democráticos.

En palabras de Teitel, la transición está asociada con la aplicación de normas en un periodo circunscrito de cambio político en los que se delimita y estructura la transición del periodo ${ }^{92}$. Dichas medidas tendrían además la vocación de proporcionar un legado más duradero, caracterizado por la reconstrucción estatal, la participación y el liderazgo político, que se convierten visiblemente en compromisos políticos renovados ${ }^{93}$.

Dichas premisas de transformación se diluyen en un proyecto gubernamental que cimienta el "Pacto por la Construcción de Paz" desde la cultura de la legalidad y la relación entre seguridad y justicia ${ }^{94}$. Resulta evidente el retorno a la política de la seguridad basada en el imperio de la ley y la persecución a la criminalidad como formas de proteger las libertades individuales.

Si bien el Plan Nacional de Desarrollo no es un espacio para hacer reconocimientos políticos, sí sorprende que la apuesta condene el secuestro y el narcotráfico, como si en el marco del conflicto armado interno no se hubieran identificado concienzudamente distintas modalidades de violencia, amenaza y violación a los derechos fundamentales contra las víctimas del conflicto y la sociedad colombiana en genera ${ }^{95}$. Reconocimientos indispensables para construir paz con justicia social y desde los territorios.

Es apenas lógico que la ruta política de Iván Duque no contemple compromisos expresos para implementar los Acuerdos de Paz logrados con la guerrilla más antigua de Colombia.

Ya por el 2006, la organización Dejusticia afirmó que el país atravesaba un proceso de justicia transicional sin transición ${ }^{96}$. Esta manifestación se hizo en

92 Teitel, R. Justicia transicional. Traducido por M. J. Viana. $1^{\text {a }}$ edición en castellano. Bogotá: Universidad Externado de Colombia, 2017. ISBN 978-958-772-760-9.

93 Ibídem, pp. 454-455.

94 Gobierno de Colombia. Bases del Plan Nacional de Desarrollo 2018-2020. Pacto por Colombia, Pacto por la Equidad [en línea]. Departamento Nacional de Planeación. Bogotá: 2019 [fecha de consulta: 4 de septiembre 2020]. Disponible en: https://id.presidencia.gov.co/ especiales/190523-PlanNacionalDesarrollo/documentos/BasespND2018-2022.pdf.

95 Centro Nacional de Memoria Histórica. ;Basta Ya! Colombia: Memorias de guerra y dignidad [en línea]. Bogotá: Centro Nacional de Memoria Histórica; Departamento para la Prosperidad Social, 2013 [fecha de consulta: 10 de agosto de 2020]. Disponible en: http://www. centrodememoriahistorica.gov.co/descargas/informes2013/bastaYa/basta-ya-colombia-memoriasde-guerra-y-dignidad-2016.pdf.

96 Uprimny, R., SAFFón, M., Botero, C. \& Restrepo, E. ¿ Justicia Transicional sin transición? Reflexiones sobre la verdad, la justicia y reparación en Colombia. [en línea]. Dejusticia. 
el marco de la implementación de la Ley de Justicia y Paz, que si bien propició la desmovilización de grupos paramilitares, no garantizaba el fin de conflicto dada la continuidad en las confrontaciones con otros actores alzados en armas.

Quince años después, no sólo no hemos podido superar la confrontación armada con grupos ilegales, sino que perdemos la oportunidad de implementar un Acuerdo de Paz que busca su implementación en medio de la inestabilidad y la polarización política. La cara más cruda del realismo político.

\section{TERCER ENFOQUE: LA APUESTA CONSTRUCTIVISTA}

Si bien Teitel ${ }^{97}$ reconoce la dicotomía entre los enfoques idealista y realista de cara a la comprensión de la justicia transicional, su propuesta trasciende las visiones "radicales" propuestas por ambos enfoques. Así, la posición de esta autora, que viene siendo retomada por varios teóricos en el campo de la justicia transicional, supone que la búsqueda de la justicia en tiempos de transición se explica mejor en términos de equilibrio de poder, esto es, a partir de una visión que logre justificar la exploración de las soluciones jurídicas propuestas por el derecho en tiempos de transición, y el contexto de transformación política.

En este sentido, y tal como lo recuerda Gómez ${ }^{98}$, Teitel aboga por la necesidad de describir, comprender y analizar la complejidad de los contextos políticos y sociales al tiempo que resalta la importancia que tienen los marcos normativos dentro de los campos social y político. De esta manera, la propuesta de la perspectiva constructivista se preocupa por observar el rol del derecho en tiempos de transición, como un verdadero potenciador de cambios políticos ${ }^{99}$. Esta última labor es cumplida especialmente por las cortes como órganos judiciales expeditos para enfrentar los problemas de incapacidad o ilegitimidad ${ }^{100}$ que sufren representantes de otros órganos estatales. Pero además de esto, tal vez la característica más importante de la apuesta constructivista consiste en tener en cuenta la participación de actores no estatales en la configuración y diseño de las medidas de transición, especialmente a través de la garantía del derecho a la participación y consulta a comunidades, organizaciones de víctimas, organizaciones de derechos humanos, ONG, entre otros.

Así lo demostró, por ejemplo, el trabajo del Ministerio de Justicia y el Derecho, a través de la Dirección de Justicia Transicional, en el que a partir de un ejercicio participativo con más de 570 líderes y lideresas regionales se indagó

Bogotá: 2006 [fecha de consulta: 4 de septiembre 2020]. Disponible en: https://www.minjusticia. gov.co/Portals/0/Foros\%20Justicia\%20Transicional/LIBRO\%20J.TRANS.pdf.

97 Ibídem, p. 19.

98 GómEz, G. Justicia transicional "desde abajo": un marco teórico constructivista crítico para el análisis de la experiencia colombiana. Revista Co-herencia. 2013, (19), 137-166 [fecha de consulta: 28 de febrero de 2019]. ISSN 1794-5887.

99 Ibídem.

100 Ibídem. 
sobre las perspectivas, expectativas y propuestas relativas a las herramientas para hacer justicia en el contexto de la transición política y el posconflicto ${ }^{101}$.

El trabajo demostró que existía un amplio respaldo por parte de los lideres a la solución política negociada del conflicto, no obstante, también se manifestaron diversas inquietudes sobre lo que se estaba negociando en ese momento en La Habana, principalmente por la falta de conocimiento sobre el estado de los acuerdos y los puntos específicos de la agenda discutida. Esta situación fue lo que motivó en buena medida que la Oficina del Alto Comisionado para la Paz iniciara toda una apuesta pedagógica para que la ciudadanía colombiana se apropiara de los contenidos del acuerdo; incluso, el documento fue traducido a 56 lenguas nativas para facilitar su conocimiento por parte de las comunidades étnicas nacionales.

Pese a estos esfuerzos, y en contra del objetivo natural de la justicia transicional, cual es propiciar que la sociedad colombiana comprenda colectivamente los diferentes procesos y mecanismos judiciales para la superación del conflicto armado interno, el logro de la reconciliación nacional y la paz duradera y sostenible ${ }^{102}$, los colombianos dijeron no al plebiscito por la paz convocado por el presidente de la república en 2016. Basset ${ }^{103}$, a través de un ejercicio de cartografía analítica, explica cómo la victoria del No se debió al voto de sectores populares urbanos, periurbanos y de las ciudades intermediarias que no se sintieron interpelados por el discurso de la paz y temieron ser olvidados en el contexto del posconflicto. Una razón más para confirmar que el modelo de justicia transicional en el país, pese a estar motivado e impulsado por diversas luchas sociales a partir de una perspectiva "desde abajo", no estuvo mediado por la construcción de acuerdos que convocaran a toda la ciudadanía colombiana, a través de una sola voz, para apoyar el fin del conflicto.

No obstante el resultado en este termómetro sociopolítico de la paz, la Corte Constitucional, en la sentencia C-379 de $2016^{104}$, ya había determinado el valor jurídico del plebiscito como mecanismo de participación ciudadana. En ese sentido, el tribunal reconoció que la decisión tomada por los ciudadanos en un plebiscito tiene un valor político. Sin embargo, los efectos de este mecanismo sólo son vinculantes para el presidente de la República, en tanto que las competencias de producción normativa para dotar de eficacia jurídica

101 Ministerio de Justicia y del Derecho. La Justicia Transicional vista desde las regiones: reporte del ejercicio de participación social para la formulación de nuevos mecanismos de Justicia Transicional en Colombia. Bogotá: Minjusticia. 2013 [fecha de consulta: 10 de diciembre de 2019].

102 Ley 1448 de 2011. Por la cual se dictan medidas de atención, asistencia y reparación integral a las víctimas del conflicto armado interno y se dictan otras disposiciones. 10 de junio de 2011. D.O n. ${ }^{\circ} 48096$.

103 BASSET, Y. Claves del rechazo del plebiscito para la paz en Colombia. Estudios Políticos. 2018, 52, 241-265 [fecha de consulta: 14 de diciembre de 2019]. Disponible en: http://www. scielo.org.co/pdf/espo/n52/0121-5167-espo-52-00241.pdf.

104 Corte Constitucional de Colombia. Sentencia C-379 de 2016. M. P. Luis Ernesto Vargas Silva: 18 de julio de 2016. 
la voluntad soberana recae en otras instancias, como en este caso, el Congreso de la República y la Corte Constitucional. De ahí que se argumente que "el límite del Estado colombiano, tanto del Pueblo soberano como de los poderes constituidos, es la Constitución", de manera que "el mandato político expresado mediante plebiscito no legitima a las autoridades para desconocer la Norma Superior". Este fue el principal argumento del Gobierno, el Congreso de la República y la Corte Constitucional para refrendar los acuerdos pactados con la exguerrilla de las FARC a través de fórmulas normativas que se ajustaran tanto a la voluntad popular como al ordenamiento jurídico y las necesidades sociales y políticas del Estado colombiano. El desarrollo y resultados del plebiscito hicieron manifiestas las tensiones entre la voluntad de la sociedad civil, del Gobierno y el órgano legislativo, así como del tribunal constitucional, encargado de interpretar y analizar el valor jurídico de lo pactado.

Otro elemento que añade complejidad a la construcción de paz desde la sociedad civil tiene que ver con la profunda polarización de la sociedad colombiana. Esta polarización trae como resultado una tendencia a criticar más severamente o a sólo criticar la violencia producida por uno de los lados del conflicto -dependiendo del lado del espectro político en el que se encuentra el crítico $^{105}$-. Como consecuencia de esta tendencia, no hay un rechazo unánime a las graves violaciones de derechos humanos cometidas por todos los actores del conflicto, rechazo que resulta esencial para lograr una paz duradera y estable ${ }^{106}$.

\section{A. La participación de las víctimas y la sociedad civil en la configuración del modelo de justicia transicional}

Una de las principales apuestas del enfoque constructivista es la de reconocer a la sociedad civil colombiana como un actor con capacidad de aportar decididamente a la construcción de paz. La historia de las últimas cinco décadas (que coincide con el inicio de los procesos de paz a nivel nacional) demuestra la reacción de la sociedad civil ante diversas políticas de Estado encaminadas a afrontar el conflicto armado interno por distintos medios. Ospina Garnica ${ }^{107}$ recuerda cómo la ciudadanía se manifestó rechazando la guerra y las formas de represión por parte del Estado implementadas a través del Estatuto de Seguridad expedido por el gobierno de Turbay a finales de los

105 UprimnY, R. y SAFFon, M. Usos y abusos de la justicia transicional en Colombia. Anuario de Derechos Humanos. 2008, (4), p. 165-195 [fecha de consulta: 8 de julio de 2019]. Disponible en: https://revistas.uchile.cl/index.php/ADH/article/view/13511/13777.

106 Ibídem.

107 Ospina, J. La participación de la sociedad civil en los procesos de paz en Colombia: retrospectiva y análisis de nuevos modelos y oportunidades. En: Bondia, D. y Muñoz, M. cord. Seguridad Humana y Construcción de Paz en Colombia. Barcelona: Editorial Huygens, 2012, pp. 98-141. ISBN: 978-84-939245-4-6. 
setenta. Dicha participación, que ha estado presente en las diversas iniciativas de paz gestadas en el país, ha dado lugar a un verdadero movimiento social que hoy recibe el nombre de Movimiento Ciudadano por la Paz en Colombia ${ }^{108}$.

Desafortunadamente, dicho rol activo de la sociedad civil se vio especialmente amenazado desde 2002, con la implantación de la política de la seguridad democrática, dado que la negación del conflicto armado interno deslegitimaba directamente los esfuerzos por construir paz desde sectores comunitarios organizados.

No obstante esta realidad, el reconocimiento de los derechos de las víctimas del conflicto armado interno logrado con la promulgación de la Ley 1448 de 2011 marcó un hito importante para la participación de las organizaciones de víctimas en el diseño de las medidas de transición. Así por ejemplo, desde el año 2011 se crea la Mesa de Participación de Víctimas a través de la cual se propicia la participación oportuna y efectiva de las víctimas en el diseño, implementación, ejecución y evaluación de las políticas de reparación integral en los niveles nacional, departamental, distrital y municipal ${ }^{109}$. La participación en dichas mesas se realiza con la concurrencia de la Personería Municipal y la Defensoría del Pueblo para los órdenes local y departamental, respectivamente ${ }^{110}$. De esta manera, la ley ordena que todas las entidades públicas encargadas del diseño y ejecución de medidas de reparación a víctimas remitan a las mesas de participación las decisiones proyectadas, de forma que éstas presenten sus observaciones y reciban las respuestas institucionales justificadas sobre los temas de que se trate ${ }^{111}$.

\section{B. El asesinato sistemático de los líderes defensores de derechos humanos}

Otra de las alertas nacionales que amenazan la apuesta constructivista de implementación de los mecanismos de transición en el país es el asesinato sistemático de líderes y lideresas sociales, defensores de derechos humanos. Para noviembre de 2018, se habían documentado 545 casos de agresión a líderes y defensores desde la firma del Acuerdo de Paz ${ }^{112}$. Mientras que en

108 Sarmiento, F., Henao, L., Hernández, C., Huertas, J. Informe especial. Movilización por la paz en Colombia: una infraestructura social clave para el posacuerdo [en línea]. Centro de Investigación y Educación Popular (CINEP). 2016 [fecha de consulta: 15 de mayo de 2020]. Disponible en: http://biblioteca.clacso.edu.ar/Colombia/cinep/20160930124827/20160302. Informe_Datapaz.pdf.

109 Ley 1448 de 2011, art. 193.

110 Ley 1448 de 2011, art. 193.

111 Ley 1448 de 2011, art. 194

112 Fundación PaZ y ReConciliación. La reestructuración unilateral del Acuerdo de Paz. A dos años de la firma del Teatro Colón. Cali: Sello Editorial Unicatólica, 2019. ISBN 978-95859836-9-4. 
el año 2019 se registraron 108 asesinatos más ${ }^{113}$. Esto hace que la cifra de homicidios ascienda a 653 líderes entre 2016 y 2019. Dicha situación revela la activación de viejas y nuevas dinámicas de violencia manifestadas en el marco de la implementación del Acuerdo. Según estudio de la Fundación Paz y Reconciliación ${ }^{114}$, los departamentos más afectados por asesinatos selectivos y sistemáticos son Cauca, Valle del Cauca y Antioquia. En su último informe sobre la situación de los derechos humanos en Colombia ${ }^{115}$, el alto comisionado de las Naciones Unidas informó que defender los derechos humanos sigue considerándose una labor de alto riesgo en el país, al tiempo que el relator especial sobre la situación de defensores de derechos humanos afirmó que Colombia es el país con mayor número de personas defensoras asesinadas en América Latina ${ }^{116}$.

Una de las cuestiones más preocupantes sobre esta persecución a líderes es que la mayoría de las víctimas pertenecen a zonas rurales y a municipios con un índice de pobreza multidimensional superior a la media nacional. Además, dichas zonas evidencian violencia endémica y presencia de economías ilícitas y de grupos al margen de la ley. Según el análisis del alto comisionado, los asesinatos se deben a la reivindicación de los derechos de las comunidades a las que los defensores pertenecen y cualquier atentado contra ellos exacerba las condiciones de marginalidad, reduciendo el surgimiento de nuevos liderazgos ${ }^{117}$. Nuevamente se encuentra que la desarticulación entre los ámbitos central y regional imposibilita la aplicación efectiva de los mecanismos de protección a líderes ${ }^{118}$.

\section{CONCLUSIÓN}

Las medidas de transición adoptadas en Colombia son producto de una relación de tensión entre actores jurídicos, políticos y sociales. Esto exige que el modelo sea analizado y legitimado a partir de diversos enfoques que ayuden a comprender la complejidad de las medidas diseñadas, pero al mismo tiempo

113 NaCiones Unidas. Consejo de Derechos Humanos. Informe anual del Alto Comisionado de Naciones Unidas para los Derechos Humanos. Situación de los derechos humanos en Colombia. A/HRC/43/3Add.3. (26 de febrero de 2020).

114 Fundación PaZ y Reconciliación. La reestructuración unilateral del Acuerdo de Paz. A dos años de la firma del Teatro Colón. Cali: Sello Editorial Unicatólica, 2019. ISBN 978-95859836-9-4.

115 NaCiones Unidas. Consejo de Derechos Humanos. Informe del relator especial sobre la situación de los defensores de los derechos humanos. A/HRC/43/51/Add.1. (26 de diciembre de 2019).

116 Ibídem, p. 1.

117 Naciones Unidas. Consejo de Derechos Humanos. Informe anual del Alto Comisionado de Naciones Unidas para los Derechos Humanos. Situación de los derechos humanos en Colombia. A/HRC/43/3Add.3 (26 de febrero de 2020).

118 Ibídem, pp. 6 y 7. 
reivindiquen la necesidad de optar por una mirada holista e integral de un proceso de configuración e implementación que ha costado tiempo, equilibrio de intereses políticos, comprensión de las demandas sociales y ponderación jurídica de principios y derechos constitucionales.

Si bien la tensión entre Derecho y poder en tiempos de transición ha sido frecuentemente mencionada por expertos y estudiosos de la materia, se hace necesario identificar dichas tensiones en el contexto colombiano en particular. Por esa razón se propuso analizar el modelo nacional a partir de tres enfoques teóricos, a saber: el realismo jurídico, el realismo político y la mirada constructivista.

Así, desde el enfoque realista jurídico es posible ver cómo los modelos de justicia transicional hacen que el Derecho deba responder a características y necesidades propias de cada país. En el caso colombiano, se trata de estrategias que han buscado la superación del conflicto armado interno y la reparación integral a las víctimas dejadas a su paso. El papel del derecho en la configuración del modelo nacional da cuenta de la función desempeñada por la Corte Constitucional al legitimar las medidas adoptadas de acuerdo con los valores, principios y derechos constitucionales, así como con los estándares internacionales en materia de derechos humanos y derecho internacional humanitario. Dicha dimensión jurídica también pasa por la constitucionalización de las medidas de transición, lo cual busca protegerlas de los cambios políticos derivados de la llegada de nuevos gobiernos presidenciales.

Por otro lado, desde el realismo político se demuestra que las políticas sobre el fenómeno de paz tomadas por el gobierno central han determinado las posibilidades de poner fin al conflicto armado por distintos medios: el enfrentamiento armado o la negociación. Del mismo modo, y pese a que esta teoría se ha caracterizado por el escepticismo a la adopción de posturas morales desde la política, el caso colombiano refleja cómo a partir del equilibrio de intereses y según las circunstancias de tiempo y lugar en que se adoptan ciertas decisiones, es posible responder a principios y derechos que guían las políticas como el reconocimiento y reparación integral de las víctimas del conflicto, la determinación de responsabilidades por las violaciones cometidas y la proposición de políticas estructurales para la no repetición.

Por último, la mirada constructivista refuerza la necesidad de interpretar y comprender la configuración del modelo nacional desde distintas perspectivas. En ese sentido, se hace un énfasis especial en los aportes que el movimiento nacional por la paz -en representación de diversos colectivos, organizaciones y la propia sociedad civil en su conjunto- ha realizado para buscar salidas al conflicto armado y el reconocimiento de las víctimas, así como para la adopción de medidas de carácter integral que nos permitan transitar realmente hacia un país más democrático y en paz. 


\section{BIBLIOGRAFÍA}

Aвuchabe, H. La justicia transicional del posacuerdo con las farC-EP. Revista Ópera [en línea]. 2017, 20, 129-153 [fecha de consulta: 12 de diciembre de 2019]. ISSN 1657-8651.

Acto Legislativo 01 de 2012. Por medio del cual se establecen instrumentos jurídicos de justicia transicional en el marco del artículo 22 de la Constitución Política y se dictan otras disposiciones. 31 de julio de 2012. D. O. n. 48.508.

Acto Legislativo 01 de 2016. Por medio del cual se establecen instrumentos jurídicos para facilitar y asegurar la implementación y el desarrollo normativo del acuerdo final para la terminación del conflicto y la construcción de una paz estable y duradera. 7 de julio de 2016. D. O. n. ${ }^{\circ} 49.927$.

Acto Legislativo 01 de 2017. Por medio del cual se crea un título de disposiciones transitorias de la Constitución para la terminación del conflicto armado y la construcción de una paz estable y duradera y se dictan otras disposiciones. 4 de abril de 2017. D. O. n. ${ }^{\circ} 50.196$.

Gobierno Nacional y farc-ep. Acuerdo final para la terminación del conflicto armado y la construcción de una paz estable y duradera [en línea]. 24 de noviembre de 2016. Disponible en: www.jep.gov.co/Marco\%20Normativo/Normativa_v2/01\%20ACUERDos/ N01.pdf.

BArberis, M. El realismo jurídico europeo-continental. En: Enciclopedia de Filosofía y Teoría del Derecho [en línea]. México: Universidad Nacional Autónoma de México, 2015 [consultado 3 de septiembre de 2020], pp. 227-240. Disponible en: https://archivos. juridicas.unam.mx/www/bjv/libros/8/3875/9.pdf.

BArberis, M. Para una teoría realmente realista del Derecho. Revista Revus [en línea]. 2016, 29, 15-23. ISSN 1855-7112.

Basset, Y. Claves del rechazo del plebiscito para la paz en Colombia. Estudios Políticos. 2018, 52, 241-265 [fecha de consulta: 14 de diciembre de 2019]. Disponible en: http:// www.scielo.org.co/pdf/espo/n52/0121-5167-espo-52-00241.pdf.

Bonilla, E. y Rodríguez, P. Más allá del dilema de los métodos: la investigación en ciencias sociales [en línea]. 3. ${ }^{a}$ ed. Bogotá: Grupo Editorial Norma, Universidad de los Andes, s.f. Disponible en: https://laboratoriociudadut.files.wordpress.com/2018/05/mas-alladel-dilema-de-los-metodos.pdf.

CABrera, E. Una tipología de realismo político. Aproximación desde el análisis conceptual. Signos filosóficos [en línea]. 2014, XVI (31), 125-155 [fecha de consulta: 31 de marzo de 2019]. ISSN 1665-1324.

Campos, F. Nociones fundamentales del realismo jurídico. Revista de Ciencias Jurídicas. 2010, 122, 191-220 [fecha de consulta: 20 de junio de 2019]. Disponible en: https:// revistas.ucr.ac.cr/index.php/juridicas/article/view/13562/12850.

CARvajal, L. Morgenthau: ¿el Maquiavelo de la política internacional? Oasis [en línea]. 2007, (12), 253-269 [fecha de consulta: 4 de abril de 2019]. Disponible en: https://revistas. uexternado.edu.co/index.php/oasis/article/view/2422. 
Centro Nacional de Memoria Histórica. ;Basta Ya! Colombia: Memorias de guerra y dignidad [en línea]. Bogotá: Centro Nacional de Memoria Histórica; Departamento para la Prosperidad Social, 2013 [fecha de consulta: 10 de agosto de 2020]. Disponible en: http://www.centrodememoriahistorica.gov.co/descargas/informes2013/bastaYa/ basta-ya-colombia-memorias-de-guerra-y-dignidad-2016.pdf.

Chaparro, A. Acordar la paz en Colombia o "la cosa misma" de la filosofía. Estudios filosóficos [en línea]. 2018, (57), 35-57. ISSN 0121-3628. Disponible en: http://www. scielo.org.co/pdf/ef/n57/0121-3628-ef-57-00035.pdf.

Constitución Política de Colombia [Const.]. Preámbulo, artículo 22. 7 de julio de 1991 (Colombia).

Corte Constitucional de Colombia. Sentencia C-370 de 2006. M. P. Manuel José Cepeda Espinosa: 18 de mayo de 2006.

Corte Constitucional de Colombia. Sentencia C-579 de 2013. M. P. Jorge Ignacio Pretelt Chaljub: 28 de agosto de 2013.

Corte Constitucional de Colombia. Sentencia C-379 de 2016. M. P. Luis Ernesto Vargas Silva: 18 de julio de 2016 .

Corte Constitucional de Colombia. Sentencia C-017 de 2018. M. P. Diana Fajardo Rivera: 21 de marzo de 2018.

De Greiff, P. Algunas reflexiones acerca del desarrollo de la justicia transicional. Anuario de Derechos Humanos, 2011, (7), 17-39 [consultado el 2 de febrero de 2019]. Disponible en: https://corteidh.or.cr/tablas/r29408.pdf.

Departamento Nacional de Planeación. Plan Nacional de Desarrollo 2002-2006, Hacia un Estado Comunitario [en línea] [fecha de consulta: 10 de junio de 2019]. Disponible en: https://colaboracion.dnp.gov.co/cdt/pnd/pnd.pdf.

FLóREZ, L. La contradicción fundamental en el movimiento critical legal studies. Revista temas sociojurídicos, 2018, vol. 37 (74), 68-84 [consultado el 9 de agosto de 2019]. ISSN: 0120-8578.

Fundación Paz y Reconciliación. La reestructuración unilateral del Acuerdo de Paz. A dos años de la firma del Teatro Colón. Cali: Sello Editorial Unicatólica, 2019. IsBN 978-958-59836-9-4.

Gobierno de Colombia. Bases del Plan Nacional de Desarrollo 2018-2020. Pacto por Colombia, Pacto por la Equidad [en línea]. Departamento Nacional de Planeación. Bogotá: 2019 [fecha de consulta: 4 de septiembre 2020]. Disponible en: https://id.presidencia. gov.co/especiales/190523-PlanNacionalDesarrollo/documentos/BasespND2018-2022.pdf.

Gómez, G. Justicia transicional "desde abajo": un marco teórico constructivista crítico para el análisis de la experiencia colombiana. Revista Co-herencia. 2013, (19), 137-166 [fecha de consulta: 28 de febrero de 2019]. ISSN 1794-5887.

Gómez, G. Justicia transicional en disputa: Una perspectiva constructivista sobre las luchas por la verdad, la justicia y la reparación en Colombia, 2002-2012. 1 $1^{\text {a }}$ ed. Medellín: Universidad de Antioquia, 2014. IsBN 978-958-714-615-8. 
IbARRA, A. Justicia transicional: la relación Derecho-poder en los momentos de transición. Revista de Derecho, 2016, (45), 237-261 [consultado el 4 de septiembre de 2020]. Disponible en: http://rcientificas.uninorte.edu.co/index.php/derecho/article/view/7176/7978.

International Center of Transitional Justice. ¿Qué es la justicia transicional? [en línea] [fecha de consulta: 8 de mayo de 2019]. Disponible en: https://www.ictj.org/es/quees-la-justicia-transicional.

Jurisdicción Especial para la Paz [en línea] [fecha de consulta: 11/11/2019]. Disponible en: https://www.jep.gov.co/Infografas/conozcalajep.pdf.

Jurisdicción Especial para la Paz [en línea] [fecha de consulta: 4 de septiembre de 2020]. Disponible en https://www.jep.gov.co/Sala-de-Prensa/Paginas/La-JEP-rechaza-sometimiento-de-Salvatore-Mancuso.aspx.

Ley 418 de 1997. Por la cual se consagran unos instrumentos para la búsqueda de la convivencia, la eficacia de la justicia, y se dictan otras disposiciones. 26 de diciembre de 1996. D. O. n. ${ }^{\circ} 43.201$.

Ley 1957 de 2019. Estatutaria de la Administración de Justicia en la Jurisdicción Especial para la Paz. 6 de junio de 2019. D. O. n. ${ }^{\circ} 50.976$.

Ley 975 de 2005. Por la cual se dictan disposiciones para la reincorporación de miembros de grupos armados organizados al margen de la ley, que contribuyan de manera efectiva a la consecución de la paz nacional y se dictan otras disposiciones para acuerdos humanitarios. 25 de julio de 2005. D.O n. 45.980.

Ley 1448 de 2011. Por la cual se dictan medidas de atención, asistencia y reparación integral a las víctimas del conflicto armado interno y se dictan otras disposiciones. 10 de junio de 2011. D.O n. ${ }^{\circ} 48096$.

Medina, C. La Jurisdicción Especial para la paz (JEP): claridades e incertidumbres de un modelo innovador de justicia transicional. Cuadernos de Estrategia [en línea]. 2017, (189), 221-232 [fecha de consulta: 11 de noviembre de 2019]. ISSN 1697-6924.

Ministerio de Justicia y del Derecho. La justicia transicional vista desde las regiones: reporte del ejercicio de participación social para la formulación de nuevos mecanismos de justicia transicional en Colombia. Bogotá: Minjusticia. 2013 [fecha de consulta: 10 de diciembre de 2019].

Melo, J. Historia Mínima de Colombia: La historia de un país que ha oscilado entre la guerra y la paz, la pobreza y el bienestar, el autoritarismo y la democracia. $1^{\mathrm{a}}$ ed. Madrid: Editorial Turner. 2017. ISBN: 978-84-16714-07-0.

Naciones Unidas. Comité de Derechos Humanos. Conjunto de principios actualizados para la protección y promoción de los derechos humanos mediante la lucha contra la impunidad. E/CN.4/2005/102/Add.1 (8 de febrero de 2005).

Naciones Unidas. Consejo de Derechos Humanos. Informe del relator especial sobre la situación de los defensores de los derechos humanos. A/HRC/43/51/Add.1 (26 de diciembre de 2019). 
NaCiones Unidas. Consejo de Derechos Humanos. Informe anual del Alto Comisionado de Naciones Unidas para los Derechos Humanos. Situación de los derechos humanos en Colombia. A/HRC/43/3Add.3 (26 de febrero de 2020).

Oficina del Alto Comisionado para la Paz [en línea] [fecha de consulta: 4 de septiembre de 2020]. Disponible en: http://www.altocomisionadoparalapaz.gov.co/Documents/ Comunicado-agosto.pdf.

Olivecrona, K. Lenguaje jurídico y realidad [en línea]. México: Distribuciones Fontamara [fecha de consulta: 3 de septiembre de 2020]. Disponible en: https://teoriageneraldelderecho122028.files.wordpress.com/2010/09/lenguaje-juridico-y-realidad-karl-olivecrona.pdf.

Oro. L. En torno a la noción de realismo político. Revista enfoques: ciencia política y administración pública [en línea]. 2009, vol. 7 (10), 15-46 [fecha de consulta: 2 de abril de 2019]. ISSN 0718-0241. Disponible en: https://dialnet.unirioja.es/servlet/articulo?codigo=3020053

Ospina, J. La participación de la sociedad civil en los procesos de paz en Colombia: retrospectiva y análisis de nuevos modelos y oportunidades. En: Bondia, D. y Muñoz, M. cord. Seguridad Humana y Construcción de Paz en Colombia. Barcelona: Editorial Huygens, 2012, pp. 98-141. ISBN: 978-84-939245-4-6.

Pezzeta, S. Derecho y sociedad. Historia y presente de los herederos del realismo jurídico estadounidense. En: Frabra, J. \& Núñez, A. (Coord.). Enciclopedia de filosofía y teoría del Derecho [en línea]. México: Universidad Nacional Autónoma de México. 2015 [consultado 20 de febrero de 2020], 667-691. Disponible en: https://archivos.juridicas.unam. $\mathrm{mx} / \mathrm{www} / \mathrm{bjv} / \mathrm{libros} / 8 / 3875 / 21 . p d f$.

Rama Judicial, República de Colombia [en línea] [fecha de consulta: 4 de septiembre de 2020]. Disponible en: https://www.ramajudicial.gov.co/web/sala-de-justicia-y-paz-tribunalsuperior-de-barranquilla/-/sobre-la-extradicion-del-postulado-salvatore-mancuso-gomezla-sala-de-justicia-y-paz-del-tribunal-superior-de-barranquilla-por-ser-un-tema-de-interes-

RECALDE, G. Repensando la iushistoria: aportes del realismo jurídico a la discusión en Revista de Derecho, 2016, vol. 1, pp. 1-16 [fecha de consulta: 8 de agosto de 2019]. Disponible en: https://una.uniandes.edu.co/images/pdf-edicion1/articulos/Recalde2016-ArtculoUNA-Revista-de-Derecho.pdf.

RettBerg, A. La construcción de paz bajo la lupa: una revisión de la actividad y de la literatura académica internacional. Estudios Políticos, 2013, vol. 42, 13-36 [consultado el 11 de septiembre de 2019]. Disponible en https://corteidh.or.cr/tablas/r31409.pdf.

Rúa, C. Los momentos de la justicia transicional en Colombia. Revista de Derecho [en línea] 2015, (43), 71-109 [fecha de consulta: 8 de julio de 2019]. ISSN 0121-8697. Disponible en: http://rcientificas.uninorte.edu.co/index.php/derecho/article/view/6270/6745.

Ruiz Rico, G. Un diagnóstico constitucional de la justicia transicional. Anuario Iberoamericano de Justicia Constitucional [en línea]. 2018, (22). 133-164 [fecha de consulta: 7 de julio de 2019]. ISSN 1138-4824.

Sarmiento, F., Henao, L., Hernández, C., Huertas, J. Informe especial. Movilización por la paz en Colombia: una infraestructura social clave para el posacuerdo [en línea]. Centro de Investigación y Educación Popular (CINEP). 2016 [fecha de consulta: 15 de mayo de 2020]. 
Disponible en: http://biblioteca.clacso.edu.ar/Colombia/cinep/20160930124827/20160302. Informe_Datapaz.pdf.

Teitel, R. Genealogía de la justicia transicional. Human Rights Journal. 2003, vol. 16 , pp. 69-94.

Teitel, R. Justicia transicional. Traducido por M. J. Viana. $1^{\text {a }}$ edición en castellano. Bogotá: Universidad Externado de Colombia, 2017. ISBN 978-958-772-760-9.

Torres, I. La trascendencia de los términos no referenciales en el lenguaje jurídico: los conceptos tu-tu. Ciencia Jurídica. 2015, 7. 141-154 [fecha de consulta: 3 de septiembre de 2020]. Disponible en: file:///Users/adminis/Downloads/Dialnet-LaTrascendenciaDeLosTerminosNoReferencialesEnElLen-5144760.pdf.

Uprimny, R., SAFFón, M., Botero, C. \& Restrepo, E. ¿ Justicia transicional sin transición? Reflexiones sobre la verdad, la justicia y reparación en Colombia [en línea]. Dejusticia. Bogotá: 2006 [fecha de consulta: 4 de septiembre 2020]. Disponible en: https://www. minjusticia.gov.co/Portals/0/Foros\%20Justicia\%20Transicional/LIBRO\%20J.TRANS.pdf.

Uprimny, R. y SAFFon, M. Usos y abusos de la justicia transicional en Colombia. Anuario de Derechos Humanos. 2008, (4), 165-195 [fecha de consulta: 8 de julio de 2019]. Disponible en: https://revistas.uchile.cl/index.php/ADH/article/view/13511/13777.

Valencia, H. Cartas de Batalla. Una crítica del constitucionalismo colombiano. Bogotá: Editorial Panamericana, 2018. IsBN: 978-958-30-3477-0. 